\author{
Military Technical College \\ Kobry Elkobbah, \\ Cairo, Egypt
}

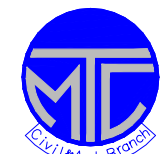

ICCAE

\author{
6hㅡ International Conference \\ On Civil \& Architecture \\ Engineering
}

\title{
STRUCTURAL HEALTH MONITORING USING TWO STAGE ALGORITHM COMBINES NON MODEL-BASED AND MODEL BASED TECHNIQUES
}

\author{
M. S. AMIN* , M. ABDELKHALIK ** , and M. K. ZIDAN***
}

\begin{abstract}
The aging of civil infrastructure and aerospace structures has led to an increased need to monitor the overall structural health. If growing damage not identified on time, it may has serious consequences, both safety related and economic. However, the complexity of large structures and the difficulty in accessing them makes the use of commonly existing conventional Non Destructive Evaluation (NDE) methods such as visual inspection and instrumental evaluation methods, impractical. An effective alternative in Structural Health Monitoring (SHM) is the use of methods that depend on Vibration-Based Damage Identification (VBDI) techniques. These methods use limited instrumentation to detect the changes in the measured modal characteristics of the structure, that is, its frequencies and mode shapes. These characteristics change with the physical properties of the structure (stiffness, mass and damping matrices) and can be used to help find the location and extent of damage. Optimal matrix update method is one of the VBDI algorithms that depends on finite element modelling (FEM) of the structure and is therefore referred to as model-based damage identification algorithm. The FRF differences method is also one of the VBDI techniques that depends on the directly measured frequency response functions data and is therefore referred to as non model-based or modal- based damage identification algorithm. However, VBDI algorithms still faces a number of challenges that have not been fully resolved. Some of these challenges are highlighted through modal tests designed to provide estimates of damage in a 3D eight-bay free-free frame. Details of tests on a healthy structure as well as on a structure in which predetermined damage has been introduced are presented. A proposed algorithm combining the aforementioned model-based and non-model based methods is introduced to improve the reliability of damage detection. The algorithm is first tested through numerical simulation to predicting damage on the basis of modal test data and the predictions are compared with the known damage.
\end{abstract}

\footnotetext{
* Ph.D, Civil Eng. Department, Military Technical College, Egyptian Armed Forces, Egypt.

** Graduate Student, Civil Eng. Department, Military Technical College, Egyptian Armed Forces, Egypt.

*** Professor, Civil Eng. Department, Faculty of Engineering, Ain Shams University, Cairo, Egypt.
} 


\title{
KEYWORDS
}

Vibration-based damage detection, structural health monitoring, frequency response function, Optimization, optimal matrix update.

\section{NOMENCLATURE}

\author{
K System stiffness matrix. \\ M System mass matrix. \\ $\delta \mathbf{K}$ Perturbations to the system stiffness matrix. \\ $\varphi_{i} \quad$ The $i^{\text {th }}$ mass-orthonormal mode shape \\ $\lambda_{i} \quad$ The $i^{\text {th }}$ eigenvalue (squared frequency). \\ $\delta \varphi_{i} \quad$ The change in the $i^{\text {th }}$ mode shape. \\ $\delta \lambda_{i} \quad$ The change in the $\mathrm{i}^{\text {th }}$ eigenvalue. \\ $\varphi_{\mathrm{d} i} \quad$ The $\mathrm{i}^{\text {th }}$ mode shape of damaged structure \\ FRF Frequency response functions
}

\section{INTRODUCTION}

Health monitoring of structures and the detection of damage at the earliest possible stage have become important issues in almost all areas of application, ranging from aerospace to civil engineering. Early detection of damage to civil engineering structures has assumed a special importance because of the aging infrastructure, increased demand, complexity and size of some of the modern structures, and lack of long-term experience with innovative materials and structural shapes that may be incorporated in a structure.

The traditional methods of damage detection include visual inspection and non-destructive instrumental evaluation. These methods require that all portions of the structure are accessible. This may be impractical, particularly when the structure is complex and/or large in size. Certain types of damage, for example, internal delamination and fibre fracture in a composite, and fracture of prestressing strands in a prestressed concrete girder cannot be detected by visual inspection. Several non-destructive damage detection techniques have been developed to detect damage that may not be visible to the naked eye. Such techniques include, for example, acoustic methods, magnetic field methods, radiography, and eddy current methods. Application of such methods requires prior knowledge of the possible damage sites and access to such sites. Also, the results of instrumental evaluation are often inconclusive or difficult to evaluate.

A comparatively recent development in the health monitoring of civil engineering structures is vibration-based damage detection. Vibration characteristics of a structure, that is, its frequencies, mode shapes, and damping are directly affected by the physical characteristics of the structure including its mass and stiffness. Damage reduces the stiffness of the structure and alters its vibration characteristics. Therefore, measured changes in the vibration characteristics can be used as indicators of the overall integrity of the structure and means of finding the location and extent of damage.

Vibration based assessment offers several advantages, one of which is that the location of damage need not be known in advance. Also, the sensors required to measure the vibration characteristics need not be located in the vicinity of the damage. In addition, a limited 
number of sensors can at times provide sufficient information to locate the damage and assess its severity, even in a large and complex structure. However, in practice there are a number of limitations associated with vibration-based damage assessment. Some of them are summarized in the following paragraphs.

Vibration-based damage identification technique (VBDI) would be successful only if damage results in a degradation of the stiffness of the structure. There are, however, instances where damage may not cause a change in stiffness. For example, failure of strands in prestressed concrete elements may still leave the section uncracked with no change in stiffness.

Vibration characteristics are global properties of the structure, and although they are affected by local damage, they may not be very sensitive to such damage. In particular the changes in the lower frequencies and mode shapes caused by local damage are often insignificant. The effect of damage on higher modes may be more substantial, but such modes are difficult to measure with accuracy.

It is impractical to measure the mode shape components along all of the independent degree of freedom (d.o.f.) of a large structure. The measured mode shapes are thus incomplete. The identification of a possible damage site and severity of damage on the basis of a change in global properties derived from measurements at a limited number of sensor locations is a problem that has a non-unique solution. Sophisticated and complex mathematical techniques including non-linear programming need to be employed to obtain the most probable solution. The optimal matrix update method is one of the VBDI algorithms that depend on finite element modeling (FEM) of the structure in which a constrained non linear optimization problem is solved and is therefore referred to as model-based damage identification algorithm. Among the identification algorithms that independent on the FEM is the FRF differences method. This method depends on the directly measured frequency response functions data and is therefore referred to as non model-based or modal- based damage identification algorithm.

The detection methods that are currently available cannot deal with situations where the damage introduces nonlinearity in the structure. Such nonlinearity may, for example result from the presence of cracks or from slippage along connections.

Global vibration characteristics are often affected by phenomena other than damage, including environmental effects, such as change of mass caused by water waves and snow accumulation, and thermal effects caused by temperature variation. The boundary conditions in a structure can have a significant effect on its stiffness, and if these boundary conditions are prone to change with the age of the structure, they may lead to a change in the vibration characteristics even when there is no damage in the structure.

A large number of research studies on VBDI have been reported in the literature [1]. A new damage identification algorithm is introduced to predict the location and severity of damage and the predicted values are assessed for their accuracy. The present study focuses on the evaluation of that algorithm which combine the aforementioned model-based and non-model based methods meant to improve the reliability of damage detection. To account for the complexity of structures that is common between aerospace and civil application, vibrationbased damage detection procedures were carried out on a 3D aluminium frame. The frame is first tested to obtain the baseline vibration characteristics of the undamaged structure. A finite element model of the structure is constructed and refined so that the analytical properties derived from the model match the measured properties. Damage of specified severity is now introduced in the specimen at predetermined locations. Next, the altered vibration 
characteristics are measured. Complete details of the testing have been presented by Amin [2].

The present paper reports in brief on the first part of the study, which is related to a computer simulation meant to test the reliability of the proposed algorithm to predicting damage on the basis of modal test data and the predictions are compared with the known damage. Details of the test specimen are provided. A 3D eight-bay free-free frame model is used to obtain the first few non-rigid-body modes shapes and corresponding frequencies of the structure, also the frequency response functions are analytically generated at several degrees of freedom. Specified damage is introduced in the model where the mode shapes and frequencies of the damaged model are computed as well as the FRF's. The damaged vibration characteristics are then used to predict the damage.

\section{THEORETICAL BACKGROUND FOR THE PROPOSED ALGORITHM}

\section{Optimal Matrix Update Method}

The theoretical basis for the optimal matrix update methods has been extensively covered in the literature $[1,3 \& 4]$. A brief description is presented here for the sake of completeness.

Vibration-based damage detection algorithms use the basic eigenvalue equation, which for the healthy structure is given by

$$
\mathbf{K} \varphi_{\mathrm{i}}=\lambda_{\mathrm{i}} \mathbf{M} \varphi_{\mathrm{i}}
$$

Damage in the structure is assumed not to cause any changes in the system mass matrix, but alters the stiffness matrix. A change in the stiffness would also change the frequencies and the mode shapes. The eigenvalue equation for the damaged structure is thus given by

$$
\left[\mathbf{K}+\boldsymbol{\delta} \mathbf{K}-\left(\lambda_{\mathrm{i}}+\delta \lambda_{\mathrm{i}}\right) \mathbf{M}\right]\left[\varphi_{\mathrm{i}}+\delta \varphi_{\mathrm{i}}\right]=\mathbf{0}
$$

On multiplying Equation 2 by piT, using Equation 1 and its transpose and rearranging terms we get

$$
\varphi_{\mathrm{i}}^{\mathrm{T}} \boldsymbol{\delta} \mathbf{K} \varphi_{\mathrm{di}}=\delta \lambda_{\mathrm{i}} \varphi_{\mathrm{i}}^{\mathrm{T}} \mathbf{M} \varphi_{\mathrm{di}}
$$

The changes in stiffness matrix $\delta \mathrm{K}$ can be expressed as the weighted sum of the stiffness matrices of the damaged elements. The weighting factors, which are the unknown in the problem, define the severity of damage in the affected elements. If the reduction in the stiffness of element $\mathrm{j}$ is expressed as $\beta \mathrm{jkj}$, we have

$$
\boldsymbol{\delta} \mathbf{K}=-\sum_{\mathbf{j}} \beta_{\mathrm{j}} \mathbf{k}_{\mathbf{j}}
$$

Substitution of Equation 4 in Equation 3 gives 


$$
\sum_{\mathrm{j}=1}^{\mathrm{n}} \varphi_{\mathrm{i}}^{\mathrm{T}} \mathbf{k}_{\mathrm{j}} \varphi_{\mathrm{di}} \beta_{\mathrm{j}}=-\delta \lambda_{\mathrm{i}} \varphi_{\mathrm{i}}^{\mathrm{T}} \mathbf{M} \varphi_{\mathrm{di}}
$$

or

$$
\mathbf{D} \beta=-\delta \lambda
$$

Where $\mathrm{n}$ is the number of elements, $\mathrm{D}$ is an $\mathrm{m}$ by $\mathrm{n}$ matrix whose elements $\operatorname{are~}_{\mathrm{ij}}=\varphi_{\mathrm{i}}^{\mathrm{T}} \mathbf{k}_{\mathrm{j}} \varphi_{\mathrm{di}} / \varphi_{\mathrm{i}}^{\mathrm{T}} \mathbf{M} \varphi_{\mathrm{di}}, \beta$ is the n-vector of the unknown changes in elemental stiffness matrices, $\delta \lambda$ is the m-vector of measured eigenvalue changes, and $\mathrm{m}$ is the number of measured modes. In general $\mathrm{m}$ will be less than $\mathrm{n}$ so that the problem defined by Equation 6 is underdetermined and has an infinite number of solutions. In order to obtain a unique solution an optimization problem needs to be solved, in which a selected objective function is minimized subjected to a specified set of constraints. In matrix update algorithms the quadratic norm of the stiffness changes given by $J=\beta T \beta$ is minimized. Equation (6) defines one set of constraints on the problem. For the damaged structure the following additional constraints must be placed on the stiffness changes

$$
0 \leq \beta \leq 1
$$

The problem defined above is a nonlinear optimization problem. In the present work the problem is solved by using an algorithm available in computer software MATLAB. The optimization routine used is based on a sequential quadratic programming method.

The number of measured modes, $\mathrm{m}$, would usually be much smaller than the number of elements, $\mathrm{n}$. In addition in a modal test it is often impractical to measure the response at all of the DOF included in a finite element model. One way to compare the analytical and experimental data is to reduce the DOFs in the analytical model or to expand the measured mode shapes to match the FEM DOFs. Reduction of DOFs in the analytical model can be carried out by using one of the standard methods, such as Guyan reduction, dynamic condensation, and system equivalent reduction expansion process (SEREP) [5]. The SEREP technique was used in the present work.

\section{Frequency Response Function Differences}

Many non model-based identification methods have been proposed to identify damage location and extent. These Methods can be divided into two main categories: Modal-data based Methods, and FRF-data based Methods. Modal-data based Methods have some shortcomings [6]. Because the modal data are indirectly measured test data, they could be contaminated by measurement errors and modal extraction errors. In addition, complete modal data cannot be obtained, practically, in most cases because this often requires a large number of sensors. In contrast with the modal data, the FRF-data will not be contaminated by modal extraction errors because the FRF-data are directly measured test data. Furthermore, the FRF-data can provide much more damage information in a desired frequency range than modal data because modal data are extracted mainly from a very limited number of FRF data around resonance [7]. Due to the apparent advantages of FRF-data over the modal data, it seems to be very promising to use measured FRF-data for identifying damages within a 
structure. Thus, motivated from the advantages of FRF-data, in the present study a Damage Detection Index DDI that interprets the differences between the FRF's measured for the healthy structure and the FRF's of the damaged structure can be used to detect the damaged region. Napolitano et al [8] have used DDI to localize damage in a typical aeronautical structure where five response points were included. The DDI is given by the following expression

$$
D D I=\sum_{j=1}^{N}\left(\frac{\sum_{i=1}^{n}\left|F I_{i}-F D_{i}\right|}{\sum_{i=1}^{n} F I_{i}}\right) \times 100
$$

Where FIi and FDi are the amplitude of the FRFs of the healthy and damaged structure respectively, $\mathrm{N}$ is the number of the intervals the sweep rang is divided into, and $\mathrm{n}$ is the number of the points in each interval FRFs are sampled in. In the present study the DDI is modified to include the whole frequency band of interest from which the $N=1$. that modification insures that all the FRF' data is included, consequently the modified DDI is reduced to the form:

$$
D D I=\left(\frac{\sum_{i=1}^{n}\left|F I_{i}-F D_{i}\right|}{\sum_{i=1}^{n} F I_{i}}\right) \times 100
$$

This non-model-based technique is characterized by its simplicity and speed in data acquisition and elaboration since it is free from modal analysis, and is able to perform a realtime monitoring of in-service structures. For numerical simulation purposes to validate the ability of the DDI, it was crucial to analytically synthesize the FRF's of both healthy and damaged structures, the theoretical basis for creating the analytical FRF's can be found in Maia et al [9] or [10]. This method is derived from the equation of motion of the forced undamped multi-degree of freedom system, which is represented by:

$$
\left(\mathbf{K}-\omega^{2} \mathbf{M}\right)\left\{\mathbf{X}_{0}\right\} \mathbf{e}^{\mathrm{i} \omega \mathrm{t}}=\left\{\mathbf{F}_{0}\right\} \mathbf{e}^{\mathrm{i} \omega \mathrm{t}}
$$

canceling the $\mathbf{e}^{\mathrm{i} \omega t}$ term and solving for the response vector $\left\{\mathbf{X}_{0}\right\}$ we get;

$$
\left\{\mathbf{X}_{0}\right\}=[\mathbf{Z}(\omega)]^{-1}\left\{\mathbf{F}_{0}\right\}
$$

where $\mathbf{Z}(\omega)=\left(\mathbf{K}-\omega^{2} \mathbf{M}\right)$ is an nxn matrix, called the mechanical impedance. Thus given the stiffness matrix $\mathbf{K}$ and mass matrix $\mathbf{M}$ for any structural system, the vector of nodal displacements can be obtained as

$$
\left\{\mathbf{X}_{0}\right\}=[\alpha(\omega)]\left\{\mathbf{F}_{0}\right\}
$$


where $[\alpha(\omega)]$ is called receptance frequency response function (FRF), and it relates the output (displacement in this case) per unit of input (excitation force in this case) at each frequency $\omega$.

\section{DESCRIPTION OF THE TEST STRUCTURE}

The test specimen used in this study is an erectable aluminium space frame made from commercially available hardware (Meroform M12). The hardware consists of standardized aluminium nodes and aluminium tube members of several different sizes. Fig. 1 shows details of the nodes and the tube. The design of the joint node allows the frame to be assembled into numerous configurations in any of three orthogonal directions, thereby providing structures with varying complexity. The members have threaded solid steel end connectors, which when tightened into the node also clamp the tube by means of an internal compression fitting. This feature allows any of the frame members to be replaced by another one of a different (smaller) size without disassembly of the entire unit, which is very useful in simulating damage in any of the members.

A finite element model of the space frame is shown in Fig. 2. The frame consists of eight bays, each of which is a cube with $707 \mathrm{~mm}$ long sides. Since the modal tests are to be conducted in a free-free condition, no supports are identified in the model. All tubes in the vertical (x-y) planes are $30 \mathrm{~mm}$ in diameter and have a wall thickness of $1.5 \mathrm{~mm}$. Tubes in the horizontal (x-z) planes, other than those already included in the vertical planes, are 22 $\mathrm{mm}$ in diameter and $1.0 \mathrm{~mm}$ thick. Lumped masses, each of $1.75 \mathrm{~kg}$, are added to nodes 4,9 , 25,28 , and 36. Masses of $2.75 \mathrm{~kg}$ are added at nodes 6, 17, and 30. Each member of the space frame is initially represented by five 3D beam elements. The internal d.o.f. in the element are then condensed out by using Guyan reduction. The resulting finite element model of the space frame possesses 216 d.o.f. Analytical studies showed that the rotational d.o.f did not contribute significantly to the strain energy of the structure and could be condensed out without introducing significant errors in the calculated frequencies and mode shapes. All of the results presented here are thus based on measurement of response along only a set of selected translational d.o.f. The system equivalent reduction expansion process (SEREP) [5] is used to condense out the d.o.f not used.

\section{FINITE ELEMENT MODEL}

The numerical simulation has been applied to a simplified FEM of the eight-bay space frame used for the experimental verification, which described in the previous section. The physical properties of the frame components are listed in Table (1). The elements are modeled using a 3D beam element, which has six translational and six rotational DOFs. The joints are modeled as being rigid. The masses of the spherical nodes, the difference between the actual mass of the element and that derived on the basis of uniform mass density, and the mass of the instrumentation attached to each node are accounted for by attaching equivalent lumped masses at the joints. To simulate the effect of the payload, added lumped masses, each having mass of $1.75 \mathrm{~kg}$ are added to nodes $4,9,25,28$ and 36 while masses of $2.75 \mathrm{~kg}$ are added to nodes 6,17 and 30 . For simplicity, rotational inertia effects of the eight lumped masses are ignored and the masses are modeled as point masses. The FEM connectivity is shown in Fig. 
2 and the elements connectivity is listed in Table 2 . The model has a total of 216 DOFs. For simplicity, the mass of the element is accounted for by using a lumped mass formulation.

\section{DAMAGE IDENTIFICATION PROCEDURES}

The study focused on a critical evaluation of the current methods of vibration-based damage identification, particularly those that known as model based methods and non-model based methods as well. The objective of this study is to develop and refine an integrated VBDI structural health monitoring procedure that combines a various analytical and experimental approaches. The algorithm adopted in this study is expected to mitigate some of the common difficulties in VBDI techniques and identify possible damage location and severity at single and multiple sites. These procedures are summarized as follows;

Step 1: The elemental stiffness and mass matrices are formulated and used to assemble the 216 DOF FEM of the undamaged structure. The modal parameters (natural frequencies and mode shapes) are then determined through the solution of the eigenvalue problem.

Step 2: Different damage cases were simulated by reducing the stiffness of the damaged elements. The FEM of the damaged structure is constructed to calculate the modal parameters of the damaged structure. Random errors are then applied to the damaged natural frequencies and mode shapes to simulate the practical situation.

Step 3: A selection for the optimum and minimum number of DOF's to serve as measurement points is carried out according to Amin [2] and found to be equal to 75 DOF's. The set of the identification modes are selected based on the strain energy stored in each mode as the first three non-rigid body modes were selected.

Step 4: The FRF's of the healthy and damaged structures at all the selected measurement DOF's due to excitation at two different points (2_y and 33_z) were created analytically using equations $(10,11 \& 12)$. Random errors were then applied to the healthy and damaged FRF's to simulate the practical situation as well.

Step 5: The damaged region is determined using the analytically created FRF's before and after the damage since the damage detection indices were calculated using equation (9) to determine the affected nodes. Consequently the elements that are connected to these nodes were considered as candidates for damage.

Step 6: In step 3, only 75 DOF's of the 216 were considered as measuring points. Consequently, the SEREP transformation matrix is formulated to reduce FEM matrices from $216 \times 216$ to the size of $75 \times 75$ to calculate the mode shapes of the healthy and damaged structure preserving the frequencies unchanged during the reduction.

Step 7: The reduced mode shapes of the undamaged and damaged structures are normalized with respect to the reduced mass matrix. Then orthogonality check is performed to pair the corresponding undamaged and damaged modes to be included in the identification process.

Step 8: The optimization problem is formulated using optimality criterion based on equations from (1) to (7) to identify damage location and extent. In this step all the 109 elements of the structures were considered as candidates for damage and included in the optimization problem as design variables.

Step 9: The optimization problem is reformulated again where the candidate elements determined in step 5 were included in the optimization problem as design variables. This step illustrates the effect of isolating the damaged area using FRF difference on the performance of the optimal matrix update in identifying different possible damaged scenarios. 
The analytical part will focus on two main issues: (1) A simple strategy was first formulated for developing and updating the FEM of the structure used in the validation of the approach, Amin [2]. (2) More than one technique (FRF differences and optimal matrix update) is then combined to improve the efficiency of damage identification algorithms in the presence of modeling and measurement errors. The proposed algorithm is then validated by applying it to a realistic large-scale structure.

In order to investigate the feasibility of the proposed algorithm, for which the theoretical background was presented earlier, a series of computer simulation and sensitivity studies were performed. A series of MATLAB codes were developed in order to implement the procedures of the algorithm. The algorithm is used to identify different levels of damage at single and multiple sites. To simulate real life structural health monitoring conditions, simulated random errors are introduced to the analytical FRF's and the analytical modal parameters (frequencies and mode shapes) for both healthy and damaged cases using MATLAB RAND function. This step is meant to test the ability of the algorithm to detect damage in the presence of the expected modeling and measurement errors. Samples of results of the computer simulation studies, which demonstrate the feasibility of different steps of the proposed algorithm, are presented here in.

\section{DISCUSSION AND CONCLUSIONS}

To test the feasibility of the proposed identification algorithm presented here, different damage cases are considered in the computer simulation. The damage cases included three groups; sever, mixed and light damage cases at single and multiple sites. Table 2 include description for each group of the different damage scenarios.

In the present study, the existence of uncertainty parameters that may shadow the performances of the identification algorithm had account for. Numerical random errors generated by MATLAB were included in the frequencies and mode shapes to simulate modeling and measurement errors applied to the modal parameters of the healthy and damaged structure as well. The values of random vector errors varying between 0.5 and $2 \%$ are applied to the frequencies, while errors between 1 and $10 \%$ are applied to the mode shape elements. The FRF's data is also corrupted with simulated random errors to simulate measuring errors.

Results of some of the damaged cases studied during the computer simulation are discussed here. Table 3 illustrate the changes in frequencies for each of the damage cases. For each of the damaged scenarios group, the FRF difference graphs are shown in Fig. 3 for illustration. Damage identification results for each damage case are shown in Fig. 4 to Fig. 6. For each damage case of the damage scenarios, Figures labeled (a) show the damage identification results using all the 109 frame elements as candidates for damage in the optimization problem. Figures labeled (d) show the damage identification results using only the candidate elements resulting from damaged region isolation in the optimization problem. Figures labeled (c) and (d), show the DDI values due to excitation at pts. (2-Y) and (33-Z) respectively related to the affected nodes. These figures used to isolate the damaged region. 
In the presence of simulated random errors, the proposed VBDI algorithm predicts the damage location and severity quite correctly for the severe damage cases at single and multiple sites (Fig. 4, $5 \& 6$ ). In the lighter damage case (Fig. $7 \& 8$ ) some of the identified members are not those with damage, but are in the same vicinity. In the mixed damaged cases, (Fig. $9 \& 10$ ) show the prediction of damage for different severities at the same damaged case. The prediction is accurate, however some of the severity values was underestimated. The FRF difference technique is applied to identify the damaged region, and the process of matrix update optimization repeated with the candidate damaged elements restricted to the region identified in the previous step concluded from figures labeled (c) and (d). Comparing the figures labeled (a) and labeled (b) proves the influence of the isolation of damaged region as the damage estimate is significantly improved. The use of FRF difference technique gave the confidence in the predicted damage elements since it is a real measurements and not affected by any source of uncertainty even in the presence of simulated random measuring errors.

\section{REFERENCES}

[1] Doebling, S. W., Farrar, C. R., Prim, M. B., and Shevitz, D. W., Damage Identification and Health Monitoring of Structural and Mechanical Systems From Changes in Their Vibration Characteristics: A Literature Review, Los Alamos National Laboratory Report LA-13070-MS., 1996.

[2] Amin, M. S., "An Integrated Vibration-Based Structural Health Monitoring System", Ph.D. thesis submitted to Carleton University, Ottawa, Canada, 2002.

[3] Hossiotis, S. and Jeong, G.D., Identification of Stiffness Reductions Using Natural Frequencies, ASCE, Journal of Engineering Mechanics, Vol. 121, No. 10, October 1995.

[4] Li, W. L., A New Method for FEM Structural Dynamic Model Updating and Joint Identification, 18th International Modal Analysis Conference, IMAC, San Antonio, Texas, Feb. 3-6, 2000, pp. 454-460.

[5] O'Callahan, J., Avitabile, P., Riemer, R. System equivalent reduction expansion process, 7th International Modal Analysis Conference, Las Vegas, Nevada, Feb. 1989.

[6] Banks, H.T., Inman, D.J. and Wang, Y., "An Experimentally Validated Damage Detection Theory in Smart Structures", Journal of Sound and Vibration, vol. 191(5), 1996.

[7] Wang, Z., Lin, R.M. and Lim, M.K. "Structural Damage Detection Using Measured FRF Data", Computer Methods in Applied Mechanics and Engineering, vol. 147, 1997.

[8] Napolitano, L., Fedele, P., Viscardi, M. and Lecce, L., "Damage Identification and Location on Typical Aeronautical Structure", SPIE Vol. 3397, 1998.

[9] Maia, N. M. M., Silva, J. M. M., He, J., Lieven, N. A. J., Lin, R. M., Skingle, G. W., to, W-M, and Urgueira, A. P. V., "Theoretical and Experimental Modal Analysis" Research Studies Press, Taunton, Somerset, England, 1997.

[10] He, J., "Structural Modification", The Royal Society journal, vol. 359, p. 187-204, 2001. 
Table 1: Nominal properties of the frame components

\begin{tabular}{|c|c|c|c|c|}
\hline $\begin{array}{c}\text { Elements per } \\
\text { plane }\end{array}$ & $\begin{array}{c}\text { Dimension } \\
(\mathrm{mm})\end{array}$ & $\begin{array}{c}\text { Area } \\
\left(\mathrm{mm}^{2}\right)\end{array}$ & $\begin{array}{c}\text { Inertia } \\
\left(\mathrm{mm}^{4}\right)\end{array}$ & $\begin{array}{c}\mathrm{wt} \\
(\mathrm{gm})\end{array}$ \\
\hline Aluminium node & 46 diameter & - & - & 80 \\
\hline Struts in (x-y) & $707 \times 30 \times 1.5$ & 134.3 & 13673 & 350 \\
\hline Struts in (x-z) & $707 \times 22 \times 1.0$ & 65.97 & 3645 & 230 \\
\hline Diagonal in (x-y) & $1000 \times 30 \times 1.5$ & 134.3 & 13673 & 450 \\
\hline Diagonal in (x-z) & $1000 \times 22 \times 1.0$ & 65.97 & 3645 & 275 \\
\hline
\end{tabular}

Table 2: Damage scenarios for different groups

\begin{tabular}{|c|c|c|c|c|}
\hline $\begin{array}{c}\text { Damage } \\
\text { Group }\end{array}$ & $\begin{array}{c}\text { Damage } \\
\text { Case }\end{array}$ & $\begin{array}{l}\text { Damaged } \\
\text { Elements }\end{array}$ & $\begin{array}{c}\text { Elements } \\
\text { Connectivity }\end{array}$ & $\begin{array}{c}\text { Damage } \\
\text { Severity } \\
\%\end{array}$ \\
\hline \multirow{6}{*}{ Sever } & DS1 & 98 & $18-21$ & 80 \\
\hline & \multirow{2}{*}{ DS2 } & 38 & $20-24$ & 80 \\
\hline & & 102 & $24-27$ & 80 \\
\hline & \multirow{3}{*}{ DS3 } & 33 & $15-19$ & 80 \\
\hline & & 37 & $19-23$ & 80 \\
\hline & & 41 & $23-27$ & 80 \\
\hline \multirow{3}{*}{ Light } & DL1 & 38 & $20-24$ & 50 \\
\hline & \multirow{2}{*}{ DL2 } & 33 & $15-19$ & 50 \\
\hline & & 37 & $19-23$ & 50 \\
\hline \multirow{5}{*}{ Mixed } & \multirow{2}{*}{ DM1 } & 37 & $19-23$ & 80 \\
\hline & & 38 & $20-24$ & 50 \\
\hline & \multirow{3}{*}{ DM2 } & 38 & $20-24$ & 50 \\
\hline & & 42 & $24-28$ & 80 \\
\hline & & 78 & $20-22$ & 80 \\
\hline
\end{tabular}

Table 3: Changes in the frequencies caused by damage

\begin{tabular}{|c|c|c|c|c|c|c|c|c|c|c|c|c|c|c|}
\hline \multirow{3}{*}{$\begin{array}{c}\text { Healthy } \\
\text { Modes } \\
(\mathrm{Hz})\end{array}$} & \multicolumn{6}{|c|}{ Sever damage Group } & \multicolumn{4}{|c|}{ Light damage Group } & \multicolumn{4}{|c|}{ Mixed damage Group } \\
\hline & \multicolumn{2}{|c|}{$\mathrm{DS} 1$} & \multicolumn{2}{|c|}{ DS2 } & \multicolumn{2}{|c|}{ DS3 } & \multicolumn{2}{|c|}{ DL1 } & \multicolumn{2}{|c|}{ DL2 } & \multicolumn{2}{|c|}{ DM1 } & \multicolumn{2}{|c|}{ DM2 } \\
\hline & $\begin{array}{l}\text { Freq. } \\
(\mathrm{Hz})\end{array}$ & $\begin{array}{c}\% \\
\Delta \omega \\
\end{array}$ & $\begin{array}{l}\text { Freq. } \\
(\mathrm{Hz})\end{array}$ & $\begin{array}{c}\% \\
\Delta \omega \\
\end{array}$ & $\begin{array}{l}\text { Freq. } \\
(\mathrm{Hz})\end{array}$ & $\begin{array}{c}\% \\
\Delta \omega \\
\end{array}$ & $\begin{array}{l}\text { Freq. } \\
(\mathrm{Hz})\end{array}$ & $\begin{array}{c}\% \\
\Delta \omega \\
\end{array}$ & $\begin{array}{l}\text { Freq. } \\
(\mathrm{Hz})\end{array}$ & $\begin{array}{c}\% \\
\Delta \omega\end{array}$ & $\begin{array}{l}\text { Freq. } \\
(\mathrm{Hz})\end{array}$ & $\begin{array}{c}\% \\
\Delta \omega \\
\end{array}$ & $\begin{array}{l}\text { Freq. } \\
(\mathrm{Hz})\end{array}$ & $\begin{array}{c}\% \\
\Delta \omega\end{array}$ \\
\hline 49.40 & 45.80 & 7.3 & 49.35 & 0.1 & 47.02 & 4.8 & 49.04 & 0.7 & 48.97 & 0.9 & 46.14 & 6.6 & 45.68 & 7.5 \\
\hline 52.96 & 52.82 & 0.3 & 44.12 & 16.7 & 42.95 & 18.9 & 51.36 & 3.0 & 50.62 & 4.4 & 49.89 & 5.8 & 48.40 & 8.6 \\
\hline 58.10 & 58.10 & 0.0 & 56.04 & 3.5 & 54.94 & 5.4 & 57.37 & 1.3 & 55.85 & 3.9 & 53.39 & 8.1 & 55.89 & 3.8 \\
\hline
\end{tabular}




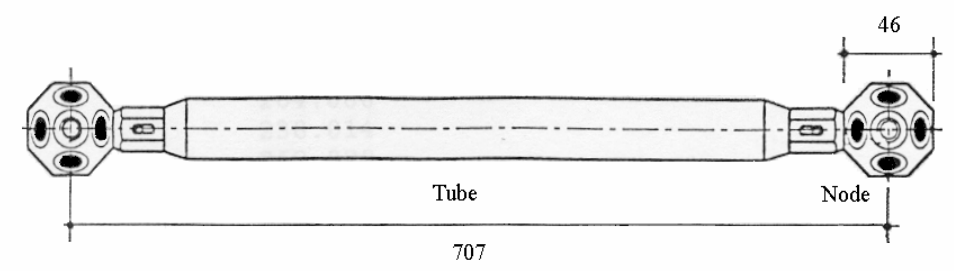

Fig. 1 Meroform aluminium tube, dimensions

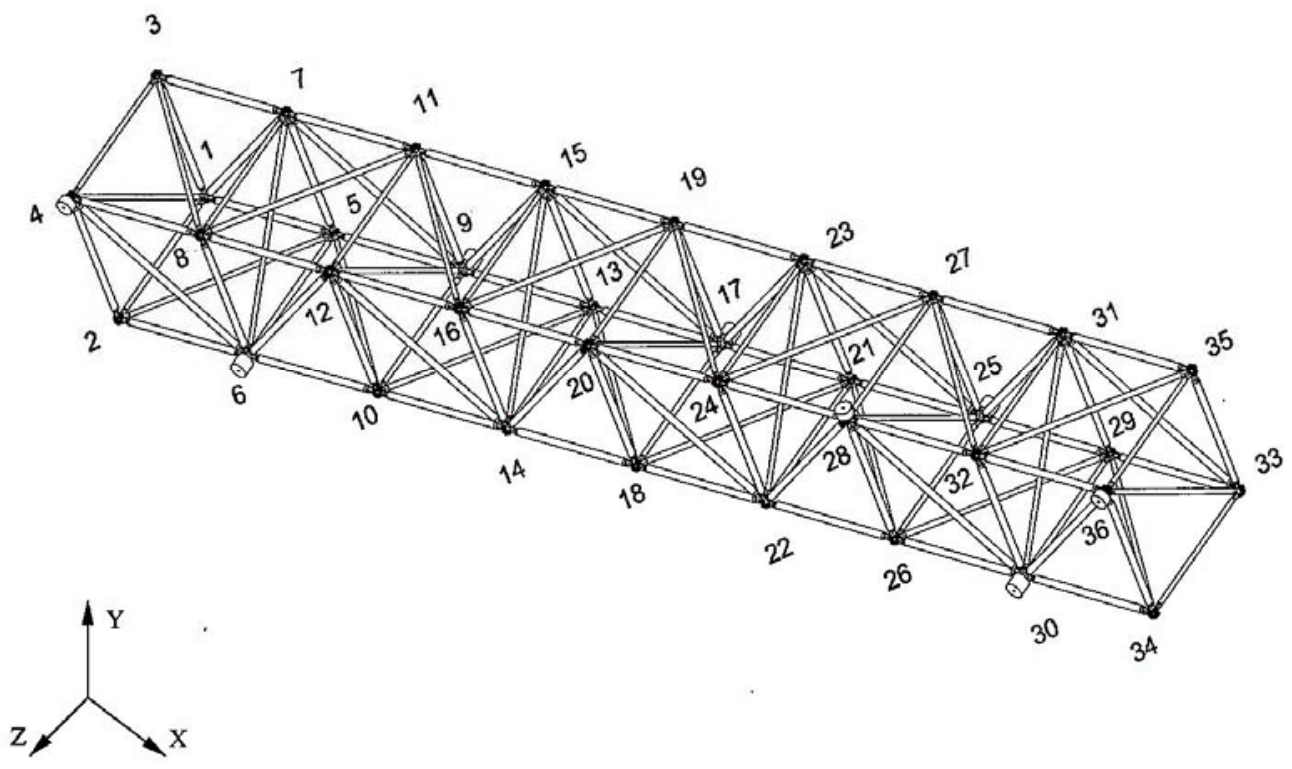

Fig. 2 : Finite element model of the space frame 


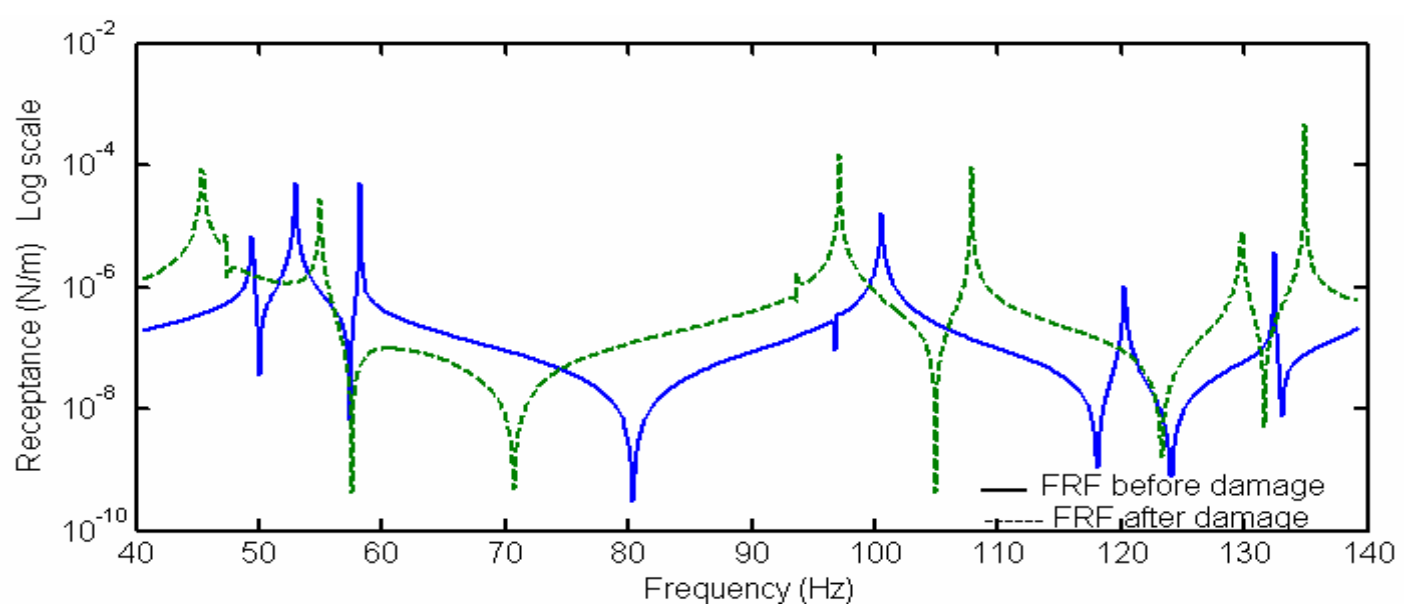

Fig. 3(a) Comparison between analytical FRFs calculated at DOF (23-x) due to excitation at DOF (2-y) for damage case DS3.

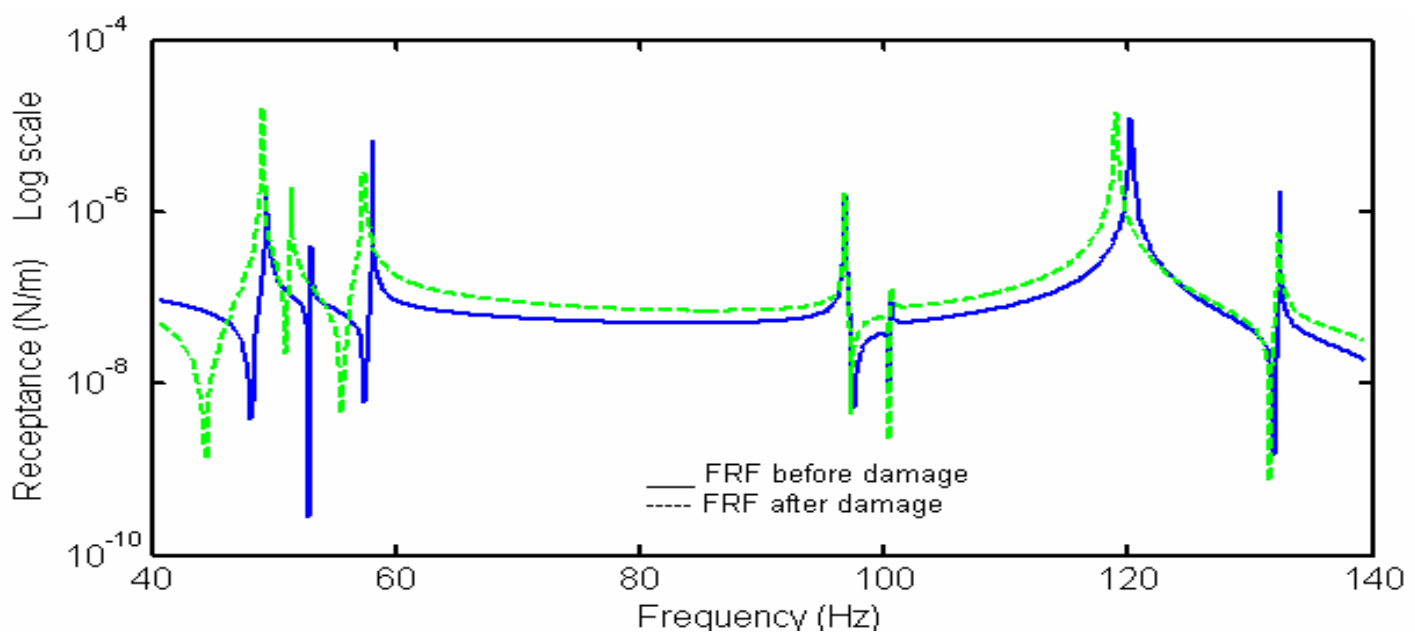

Fig. 3(b) Comparison between analytical FRFs calculated at DOF (20-x) due to excitation at DOF (2-y) for damage case DL1.

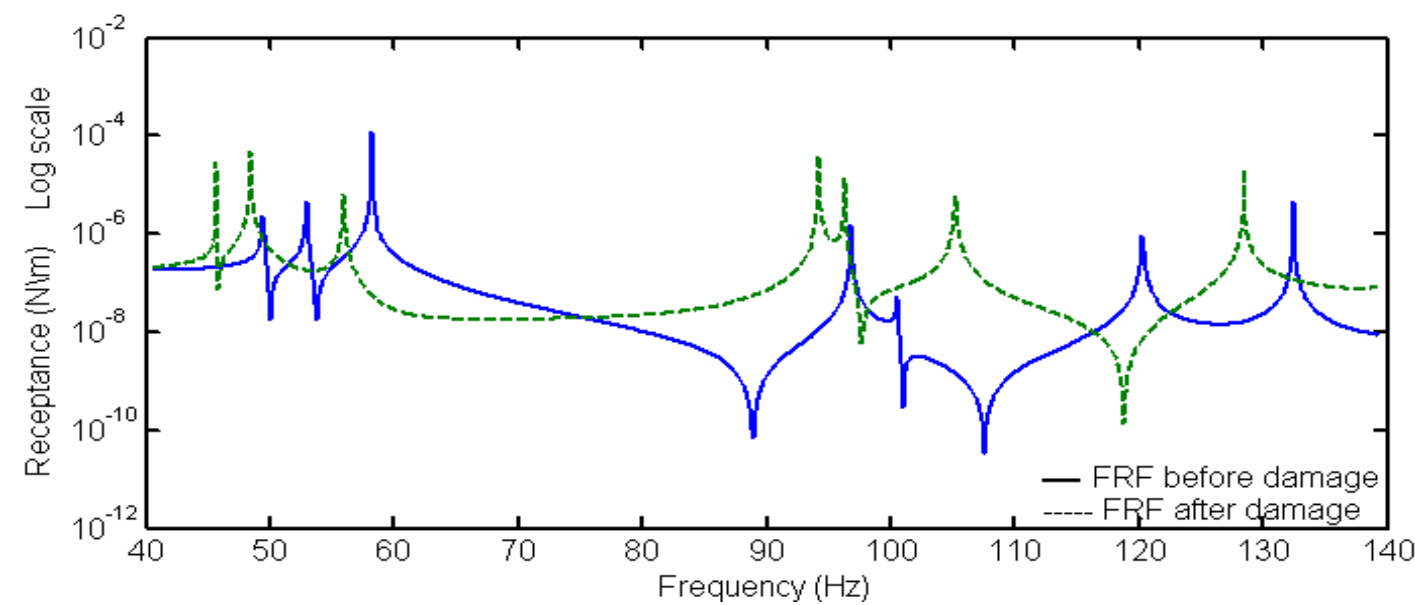

Fig. 3(c)Comparison between analytical FRFs calculated at DOF (24-x) due to excitation at DOF (2-y) for damage case DM2. 
Proceedings of the 6th ICCAE Conf. 16-18 May, 2006

\begin{tabular}{|l|l|}
\hline SAD8 & 115 \\
\hline
\end{tabular}

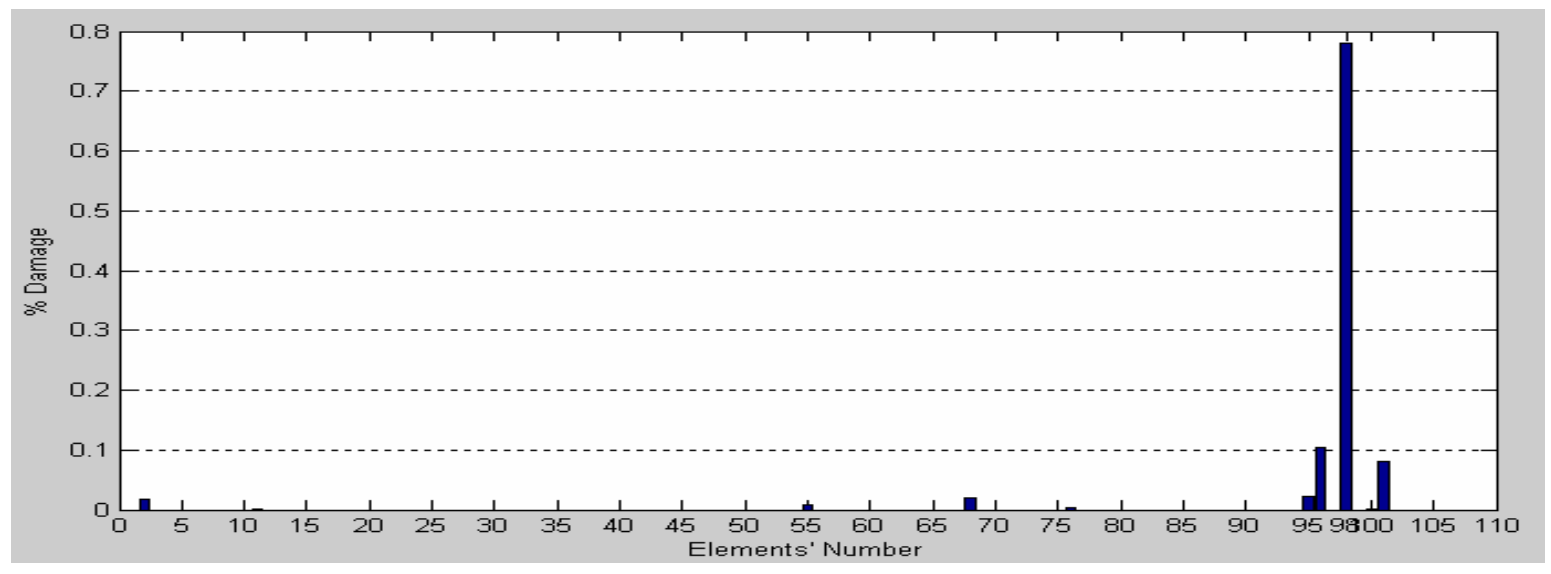

Fig. 4 (a) Damage identification results for damage case DS1 using 109 elements

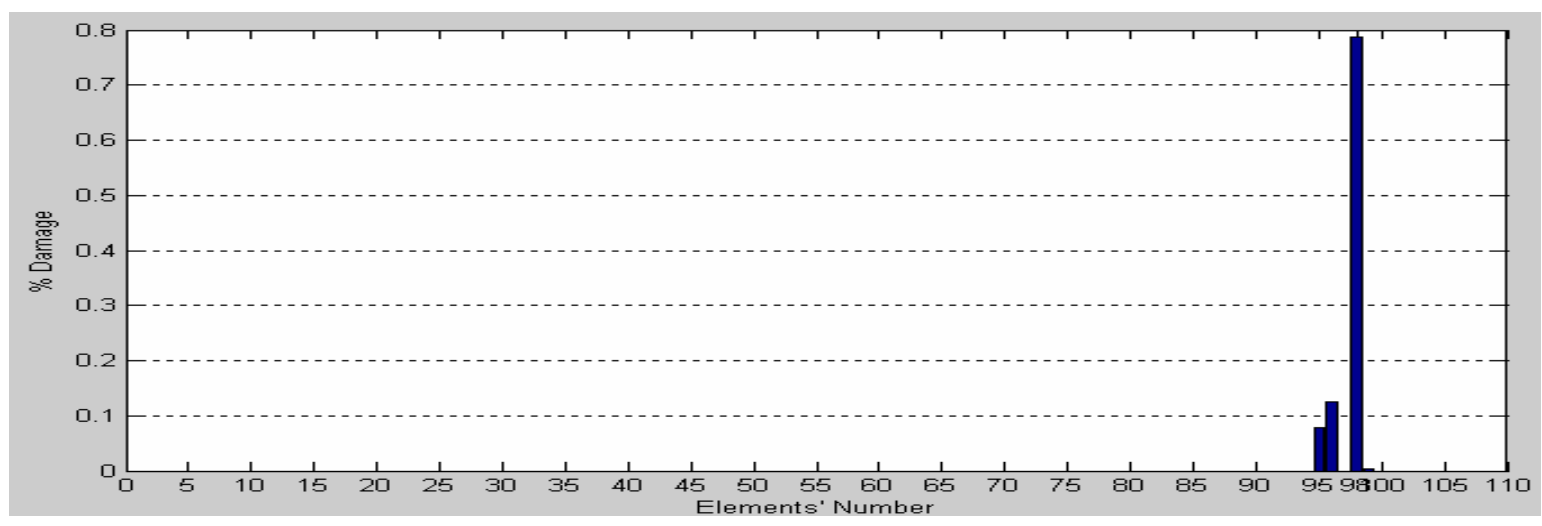

Fig. 4 (b) Damage identification case DS1 based on damaged region identification using DDI 


\begin{tabular}{|l|l|}
\hline SAD8 & 116 \\
\hline
\end{tabular}

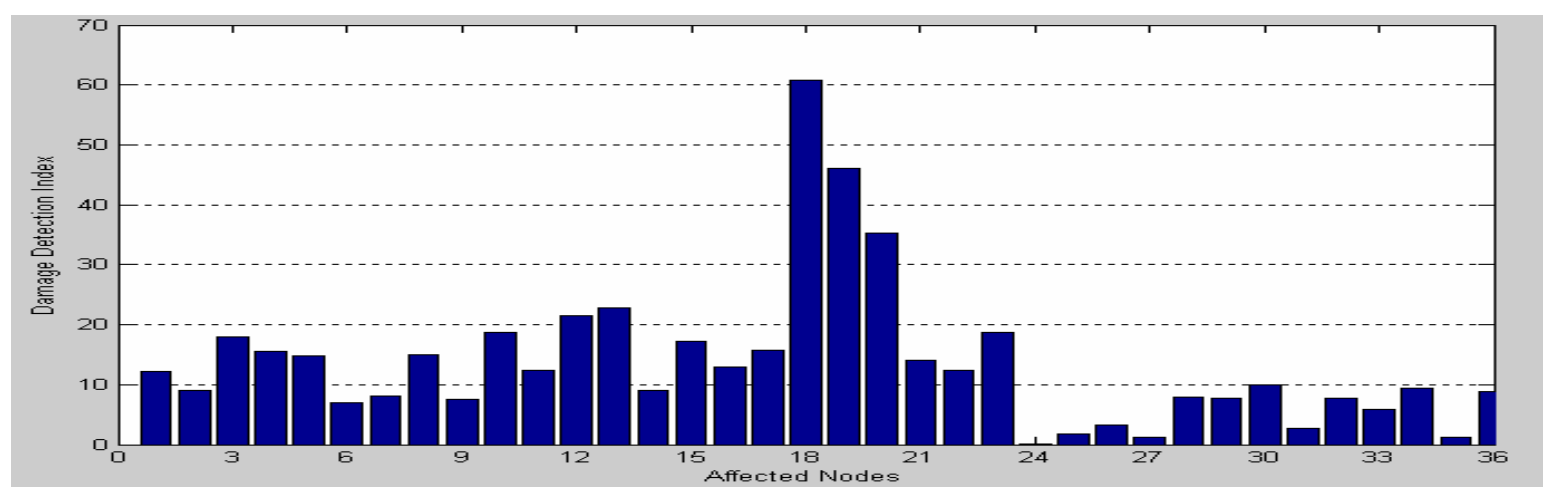

Fig. 4 (c) DDI values case DS1 using FRFs at translational x-axis due to excitation at (2-y)

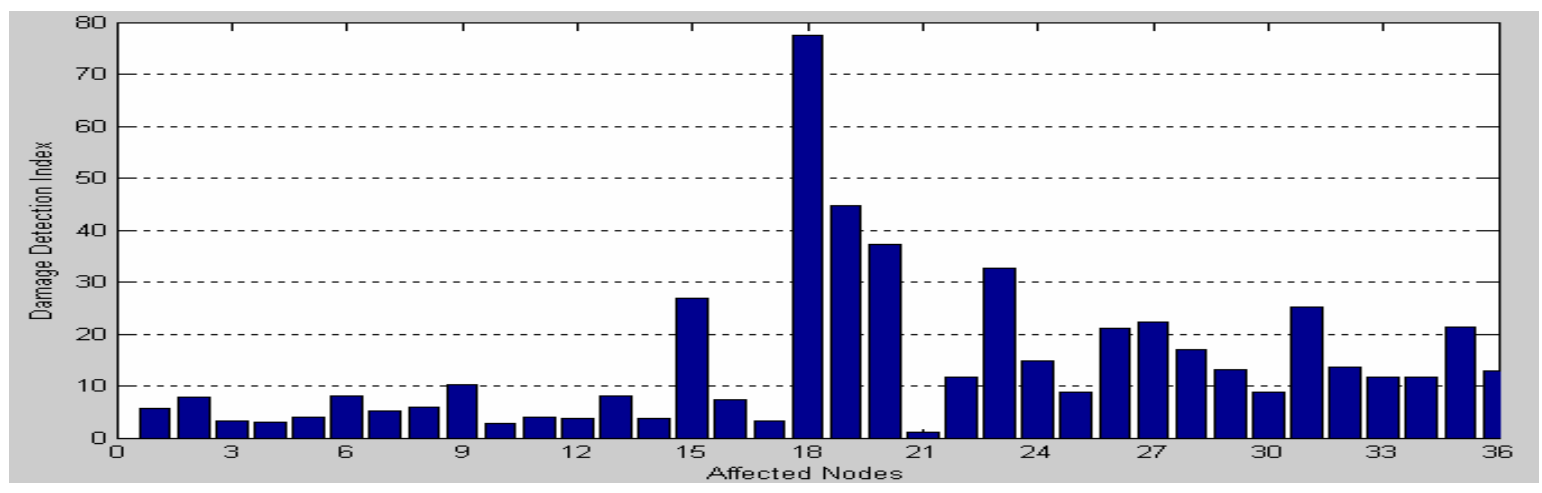

Fig. 4 (d) DDI values case DS1 using FRFs at translational x-axis due to excitation at (33-Z) 


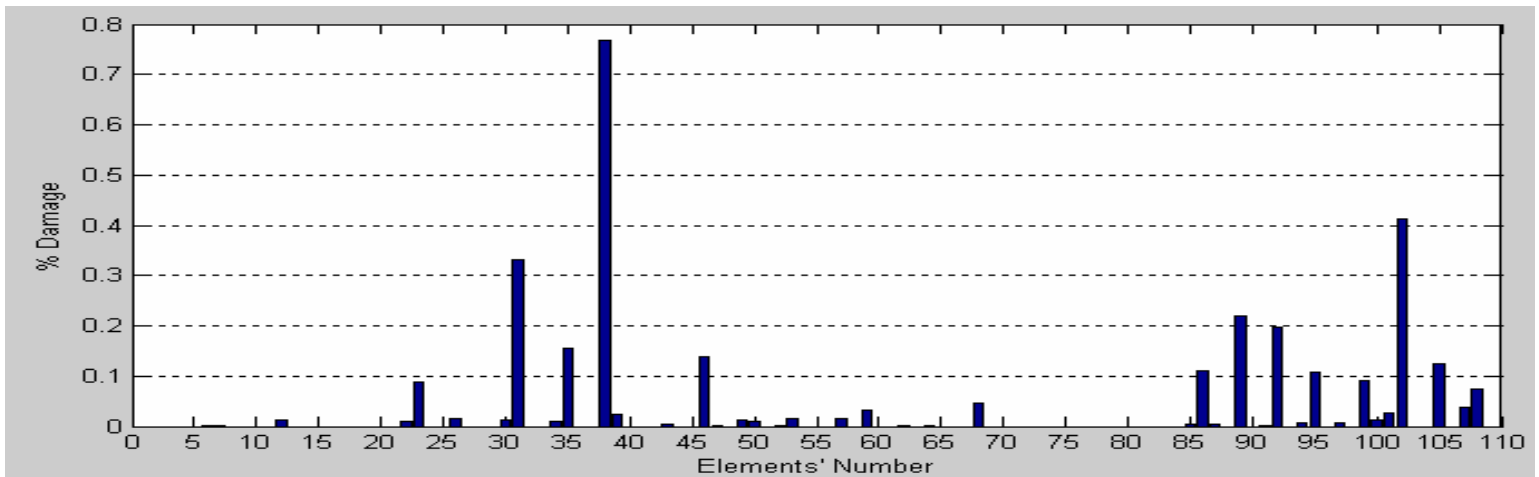

Fig.5 (a) Damage identification results for damage case DS2 using 109 elements

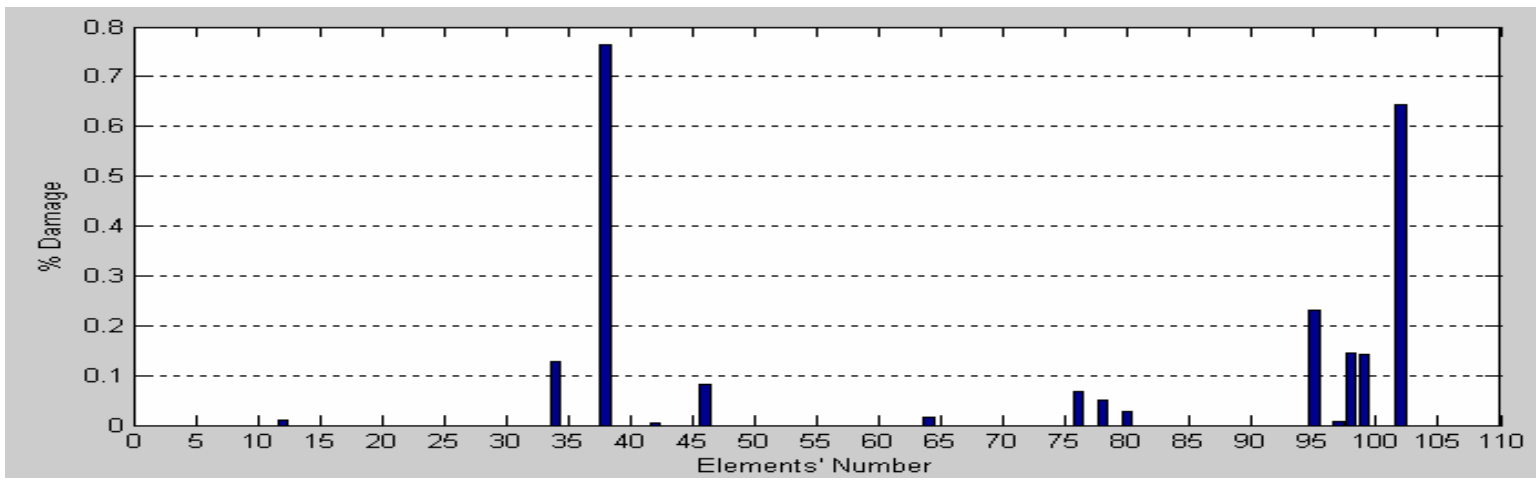

Fig. 5 (b) Damage identification case DS2 based on damaged region identification using DDI

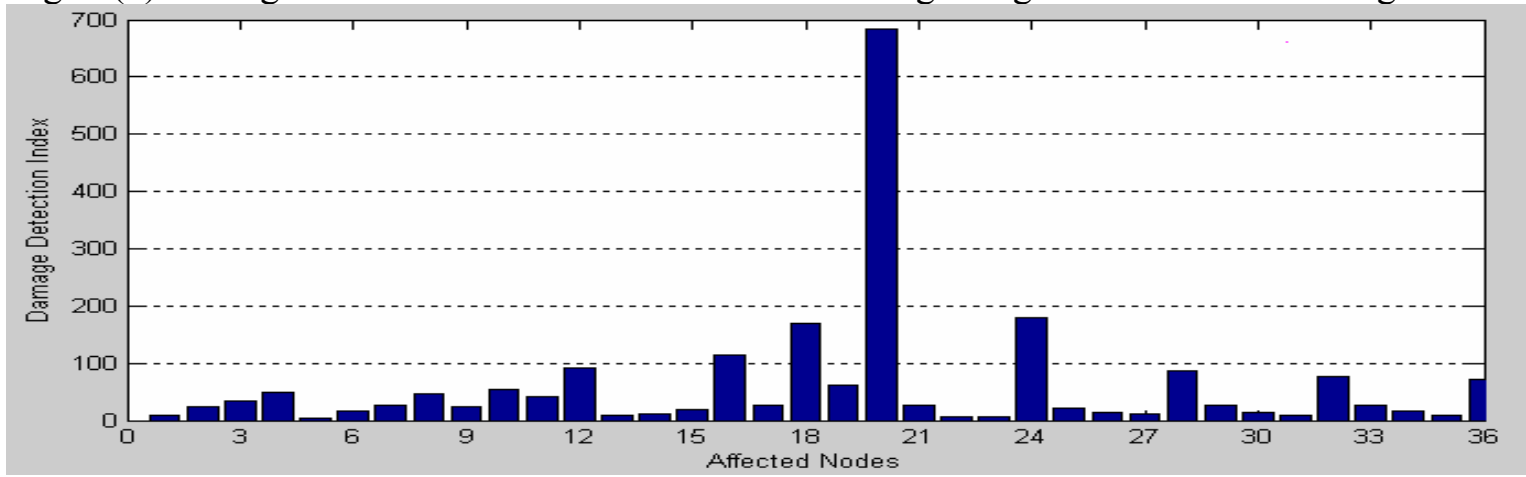

Fig. 5 (c) DDI values case DS2 using FRFs at translational x-axis due to excitation at (2-y)

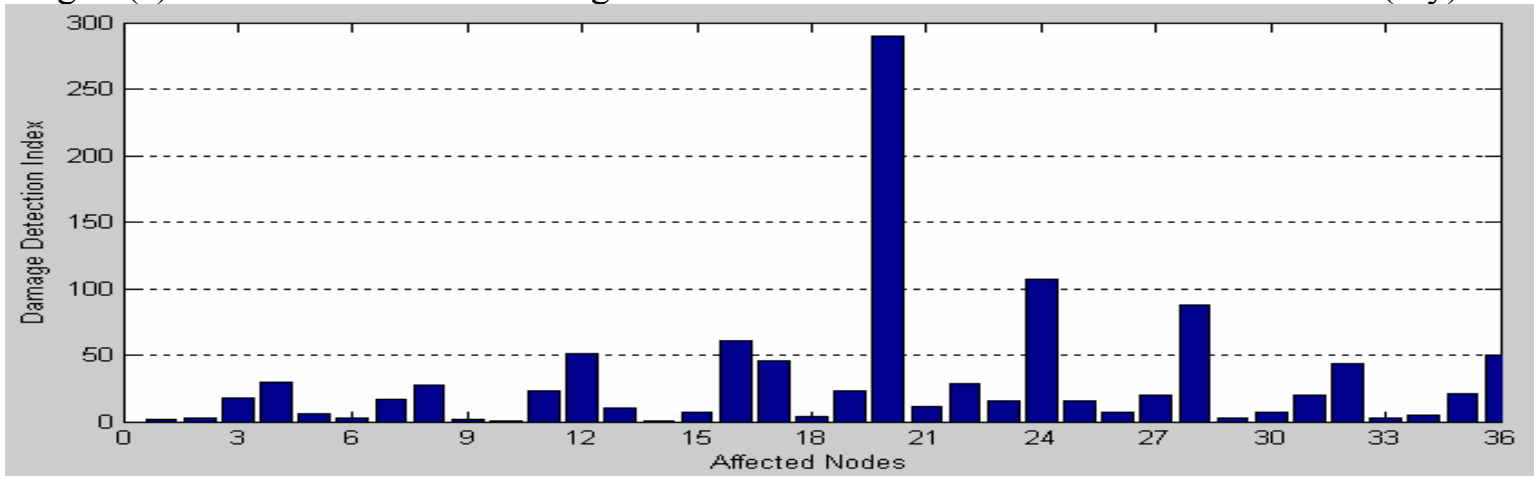

Fig. 5 (d) DDI values case DS2 using FRFs at translational $\mathrm{x}$-axis due to excitation at (33-Z) 


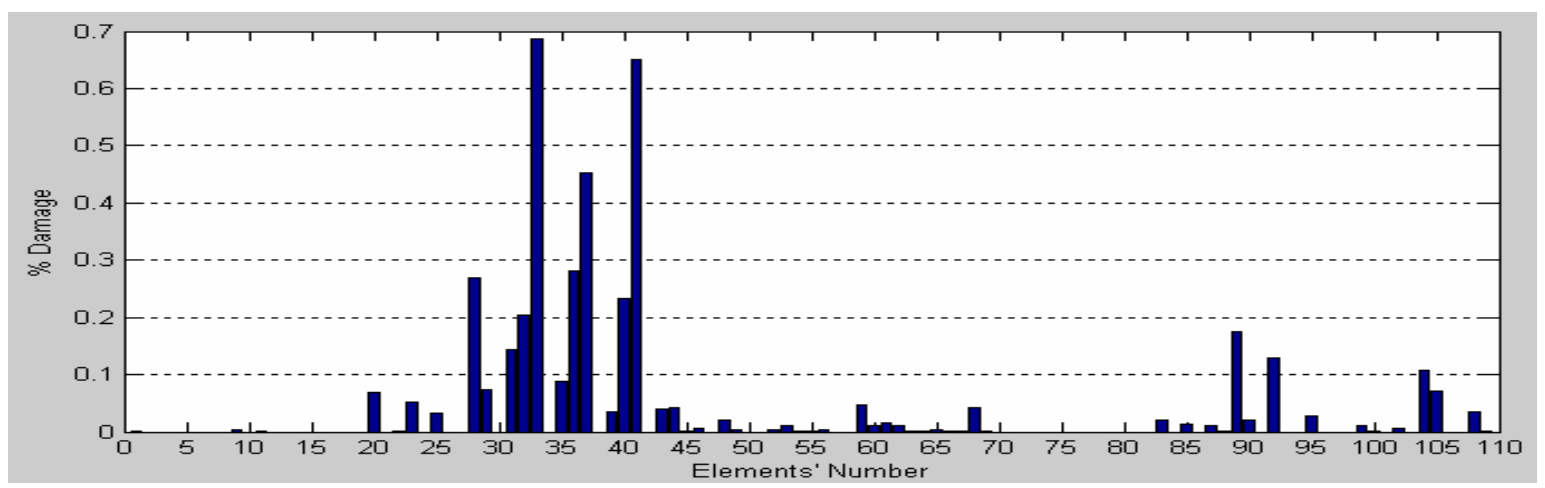

Fig. 6 (a) Damage identification results for damage case DS3 using 109 elements

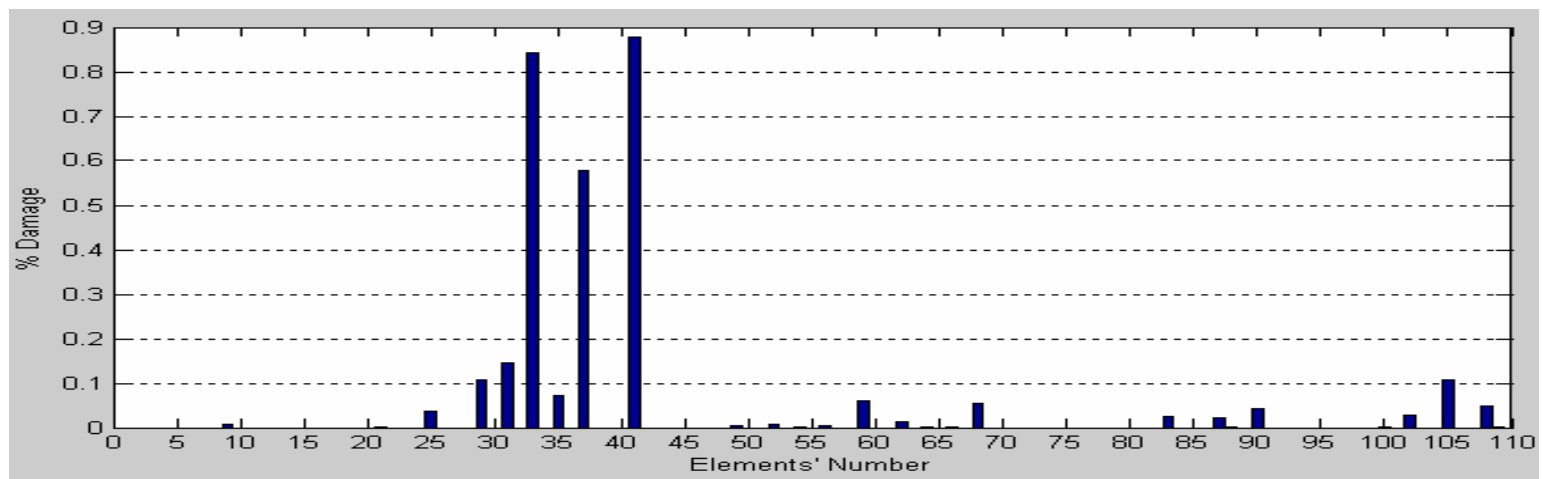

Fig. 6 (b) Damage identification case DS3 based on damaged region identification using DDI

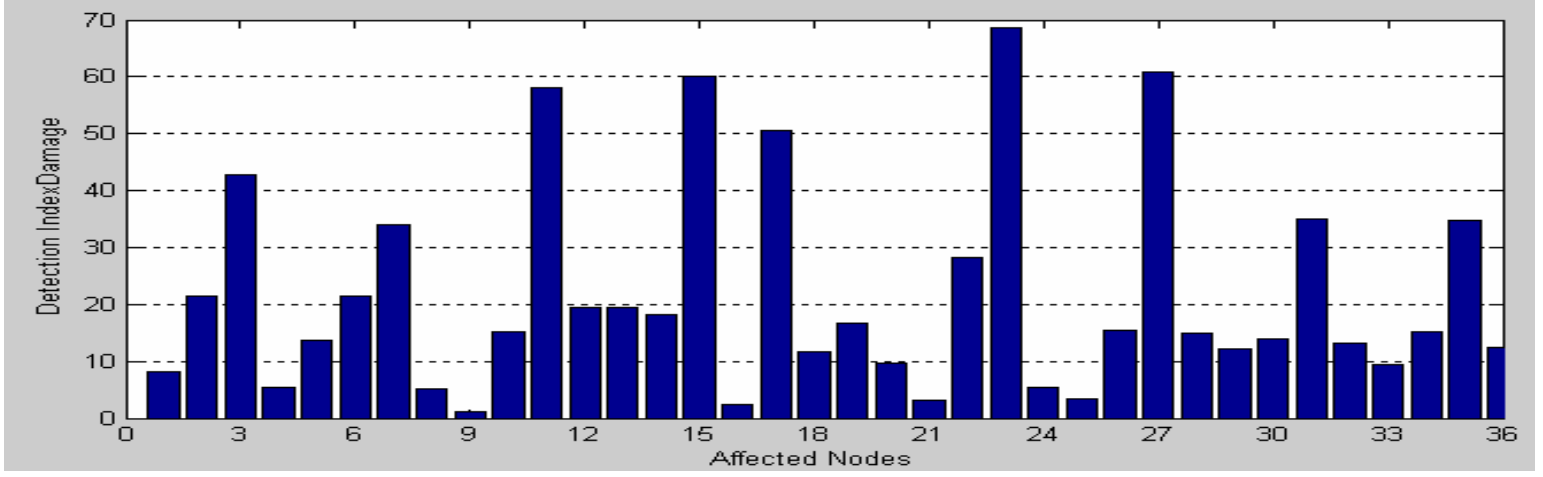

Fig. 6 (c) DDI values case DS3 using FRFs at translational x-axis due to excitation at (2-y)

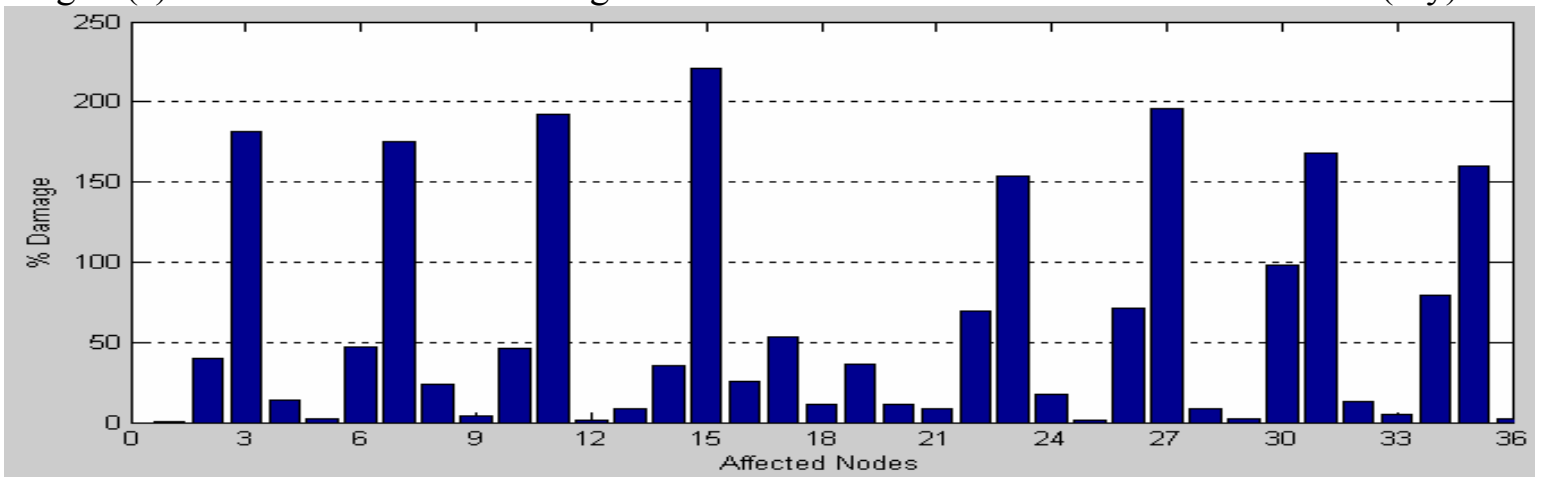

Fig. 6 (d) DDI values case DS3 using FRFs at translational x-axis due to excitation at (33-Z) 


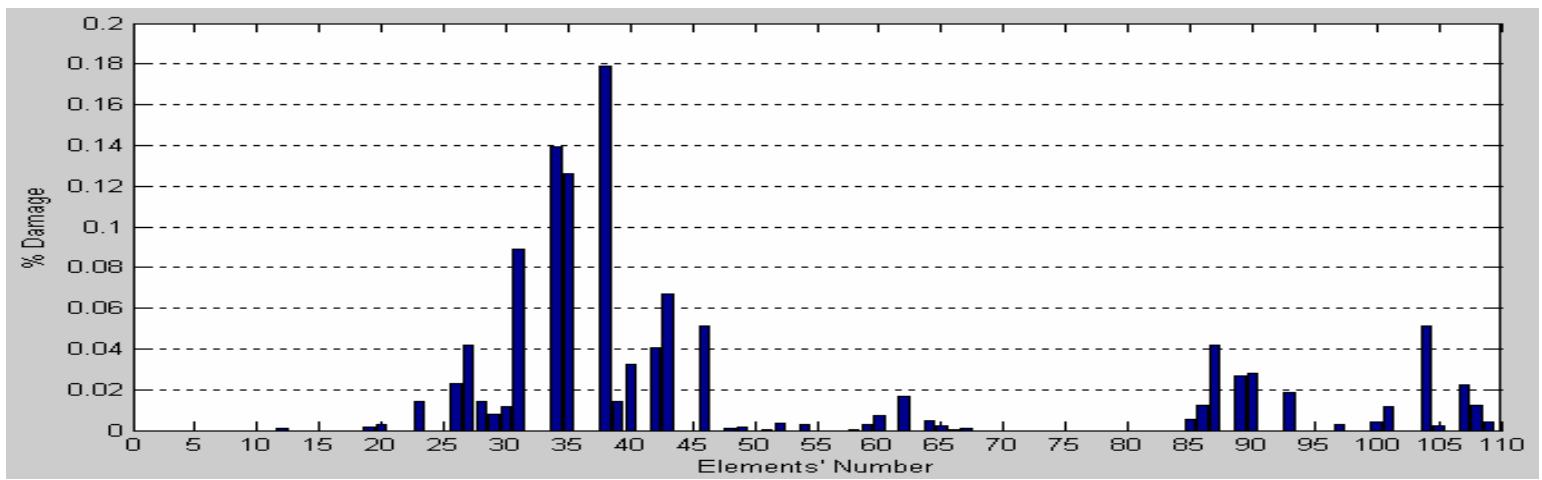

Fig.7 (a) Damage identification results for damage case DL1 using 109elements

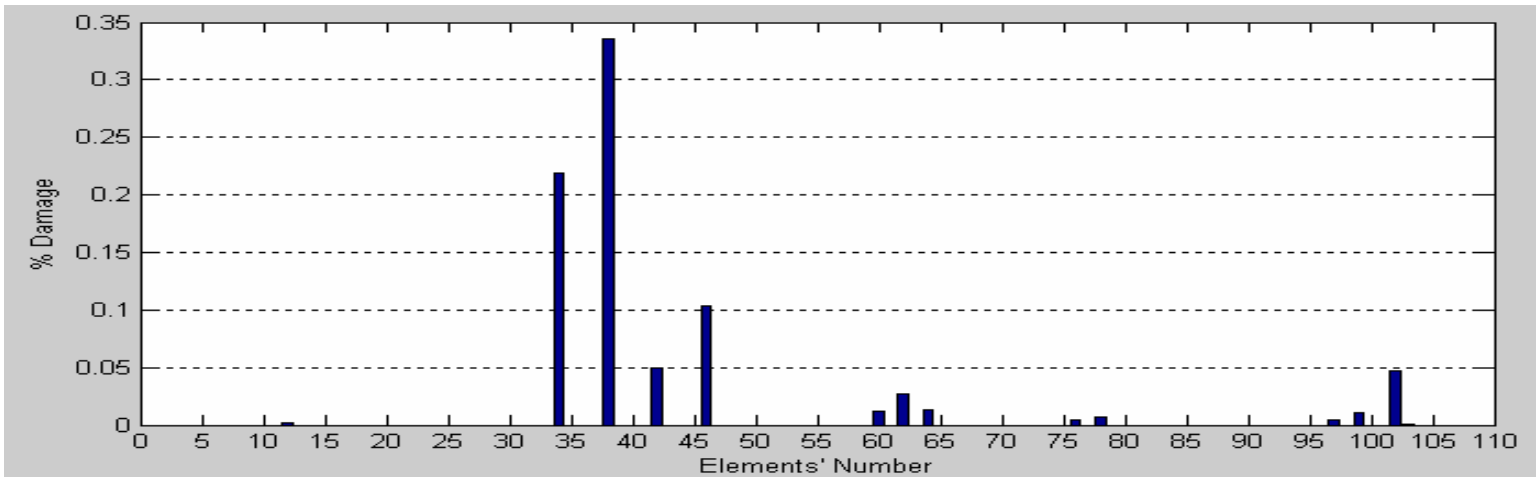

Fig. 7 (b) Damage identification damage case DL1 based on region identification using DDI

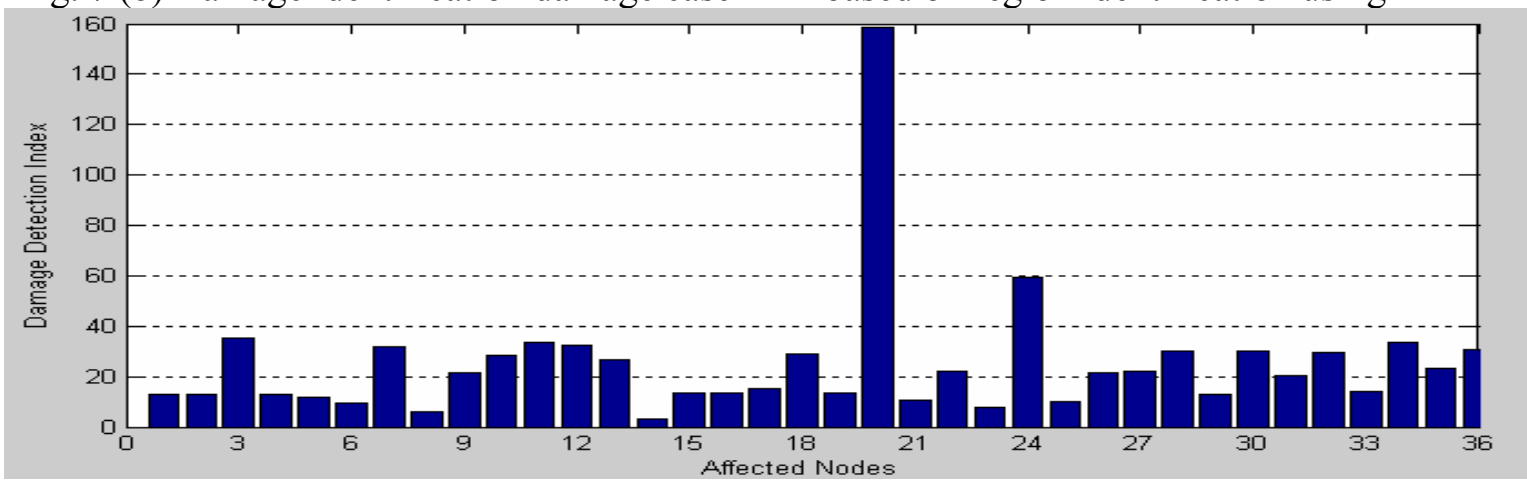

Fig. 7 (c) DDI values case DL1 using FRFs at translational x-axis due to excitation at (2-y)

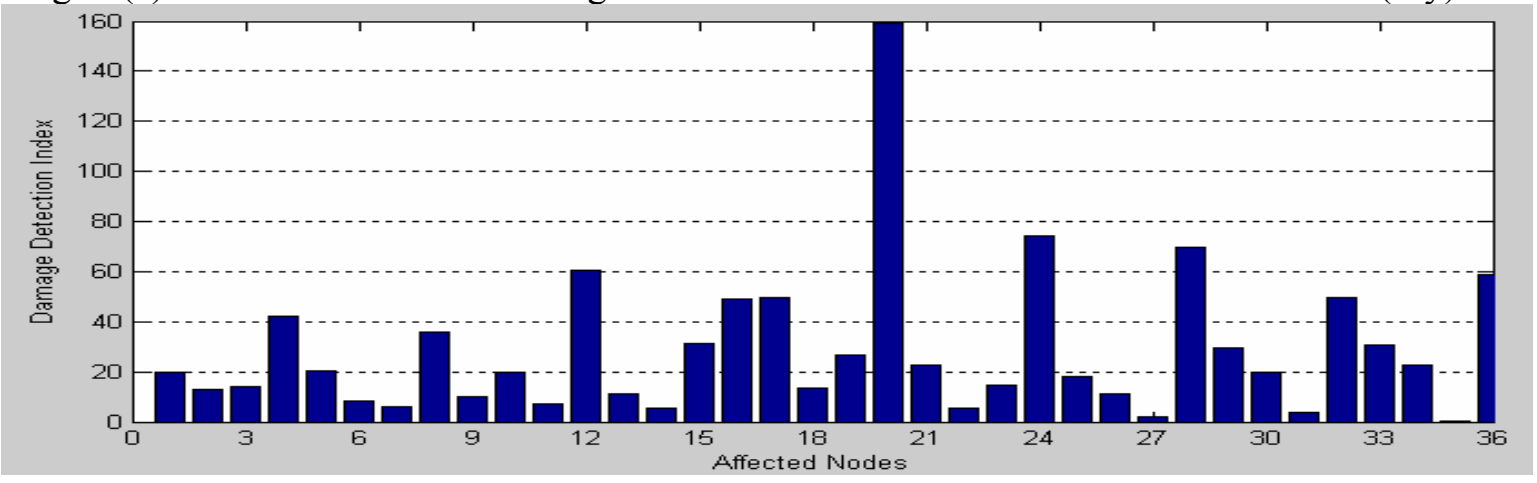

Fig. 7 (d) DDI values case DL1 using FRFs at translational x-axis due to excitation at (33-Z) 
Proceedings of the $\mathbf{6}$ th ICCAE Conf. 16-18 May, 2006

\begin{tabular}{|l|l|}
\hline SAD8 & 120
\end{tabular}

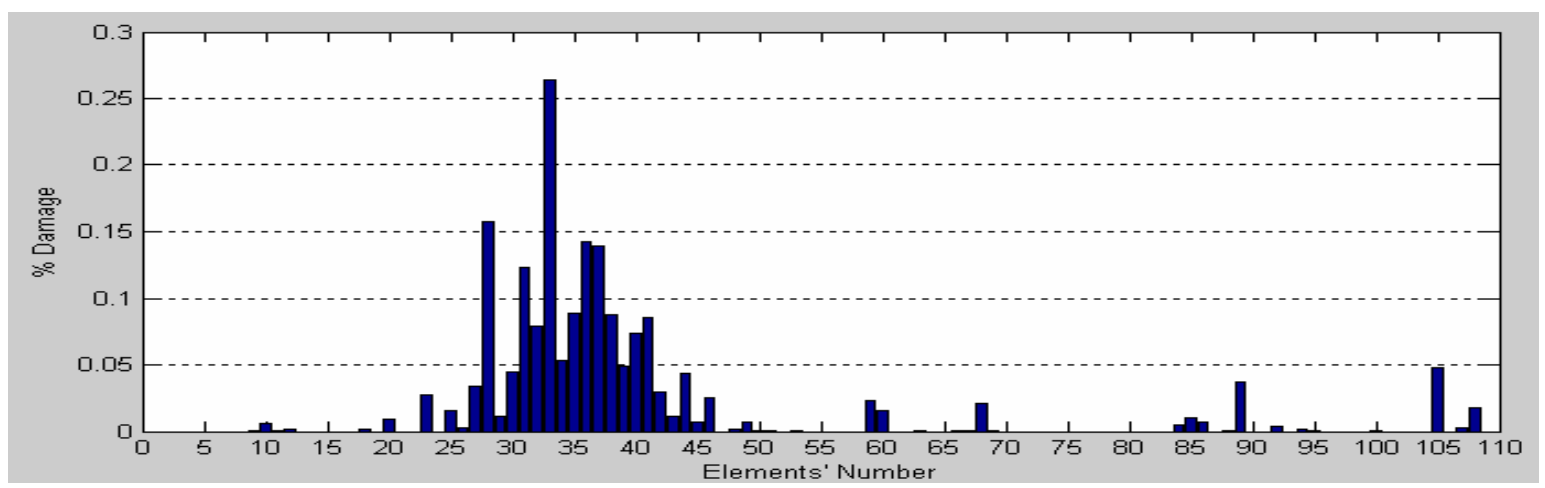

Fig. 8(a) Damage identification results for damage case DL2 using 109elements

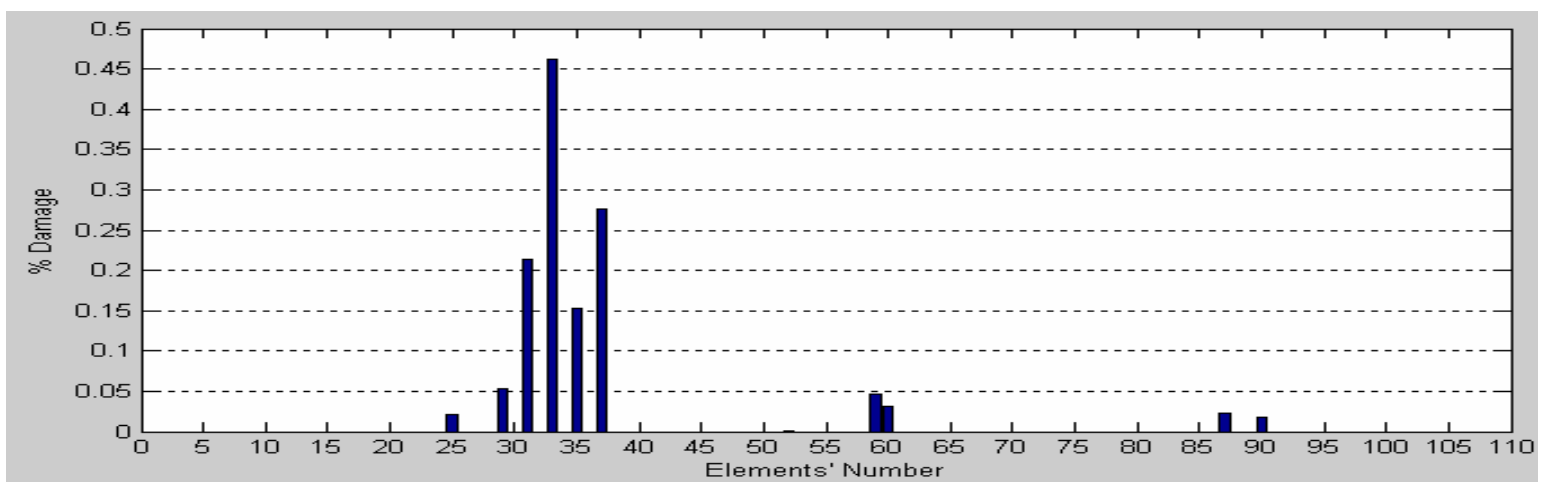

Fig. 8(b) Damage identification case DL2 based on region identification using DDI

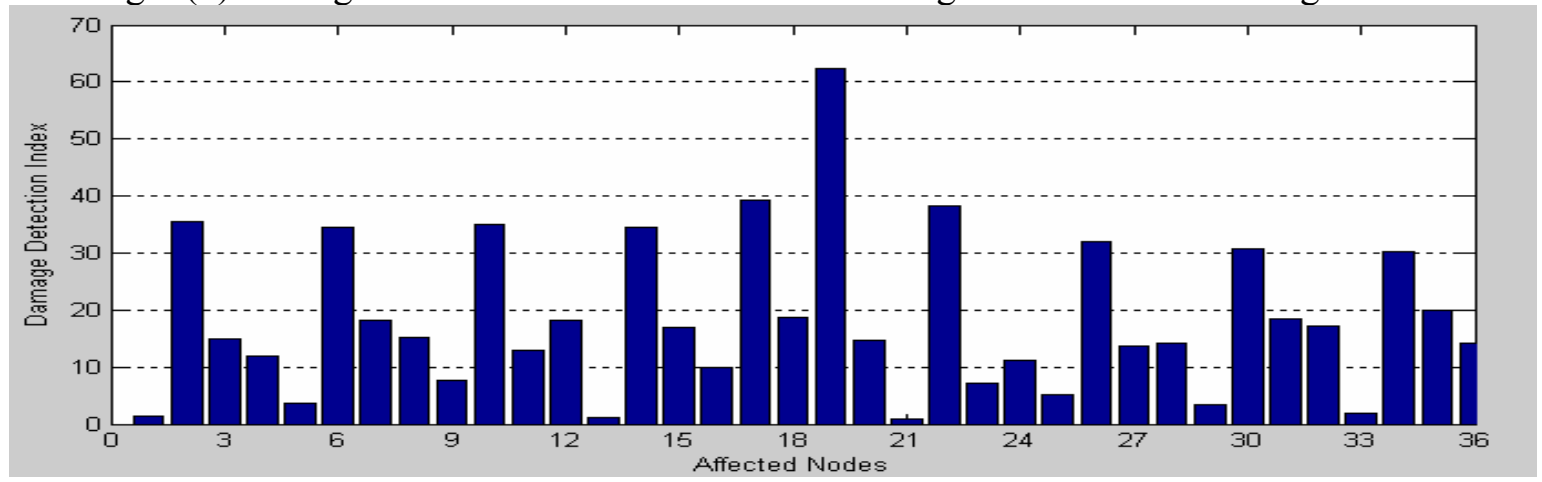

Fig. 8 (c) DDI values case DL2 using FRFs at translational x-axis due to excitation at (2-y)

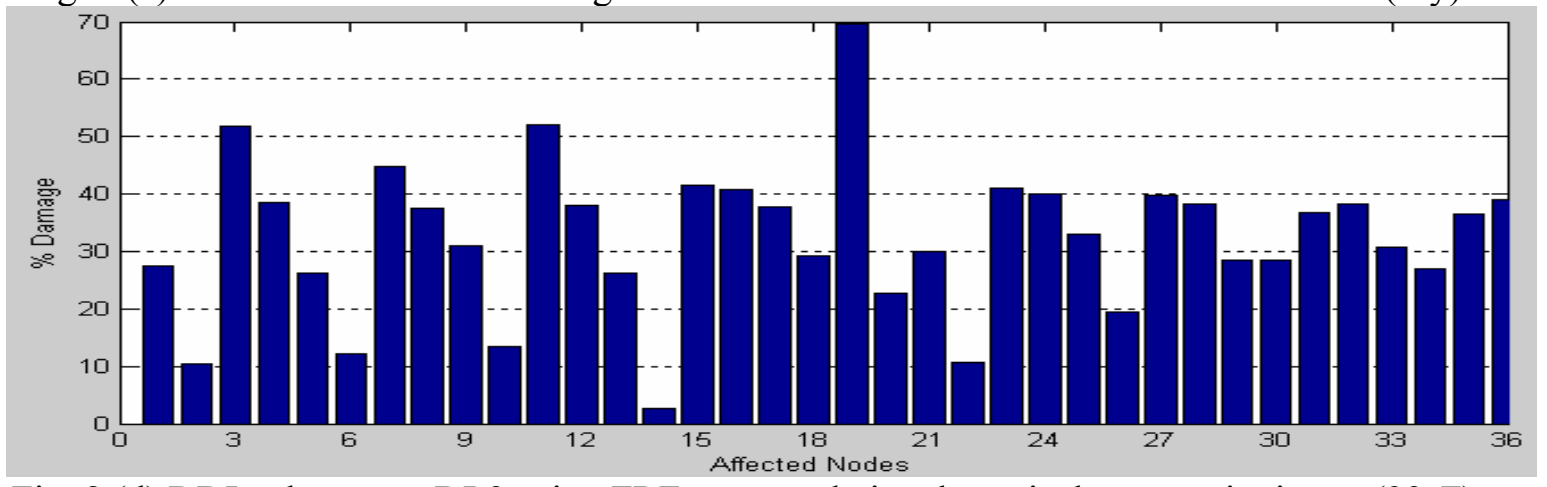

Fig. 8 (d) DDI values case DL2 using FRFs at translational x-axis due to excitation at (33-Z) 


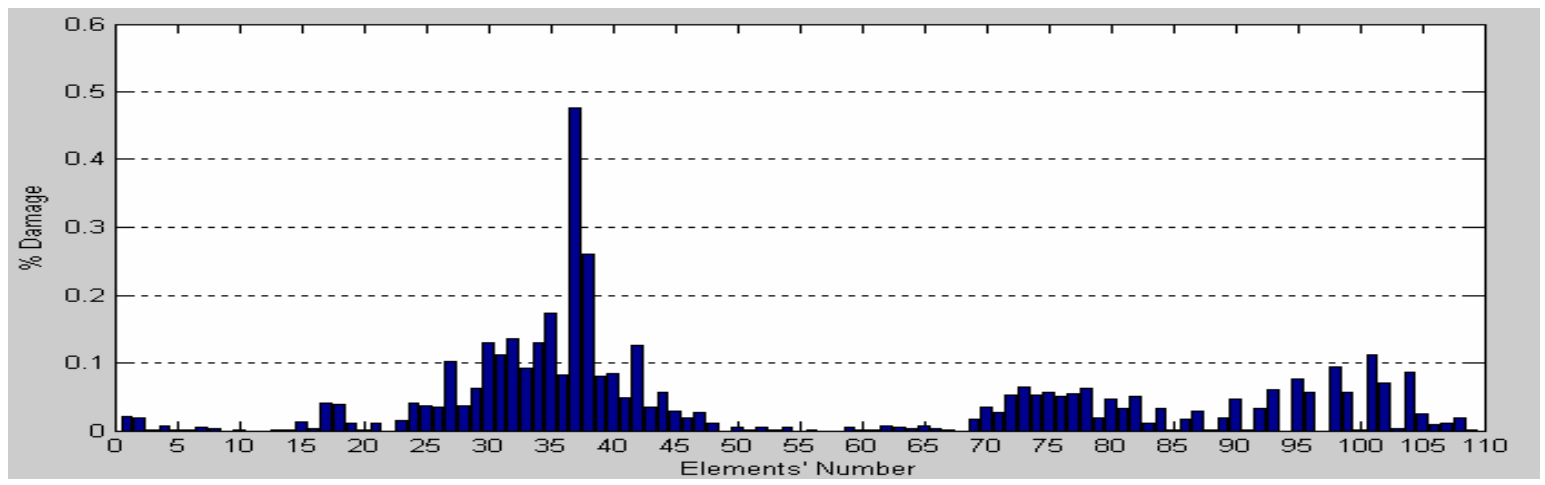

Fig. 9 (a) Damage identification results for damage case DM1 using 109elements

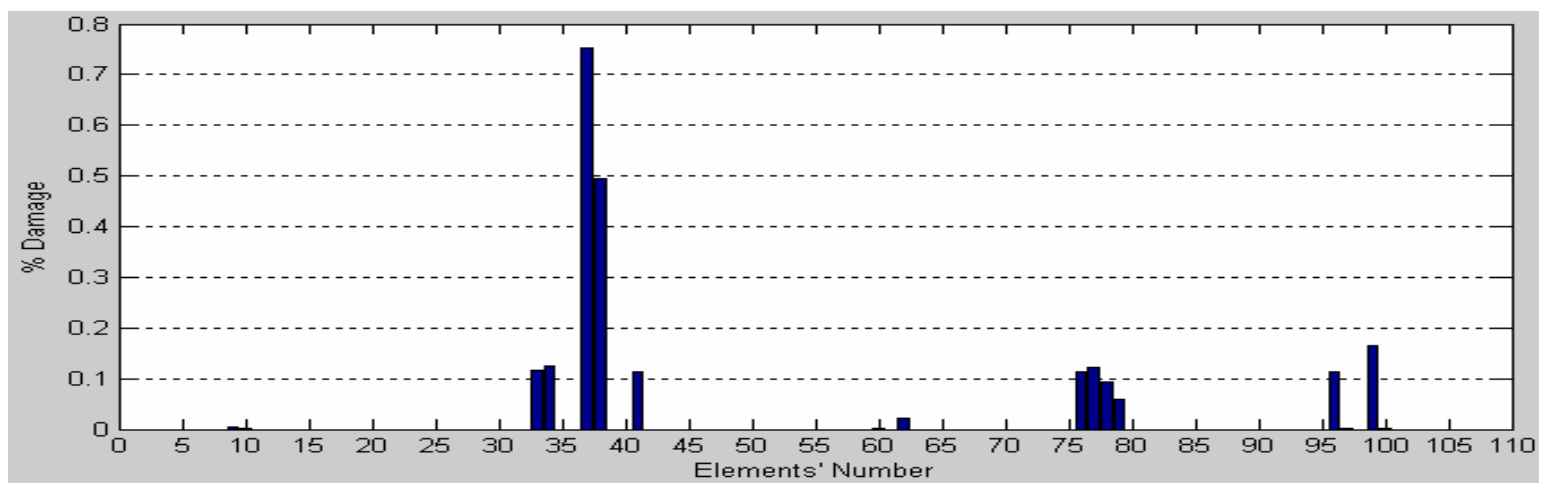

Fig. 9 (b) Damage identification case DM1 based on region identification using DDI

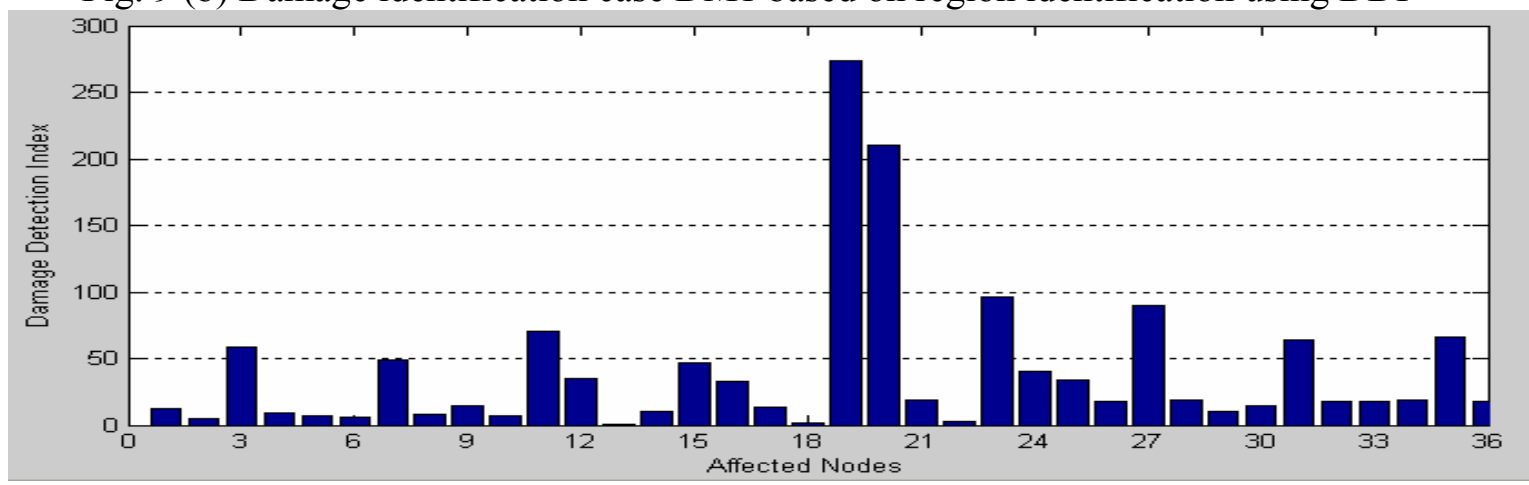

Fig. 9 (c) DDI values case DM1 using FRFs at translational x-axis due to excitation at (2-y)

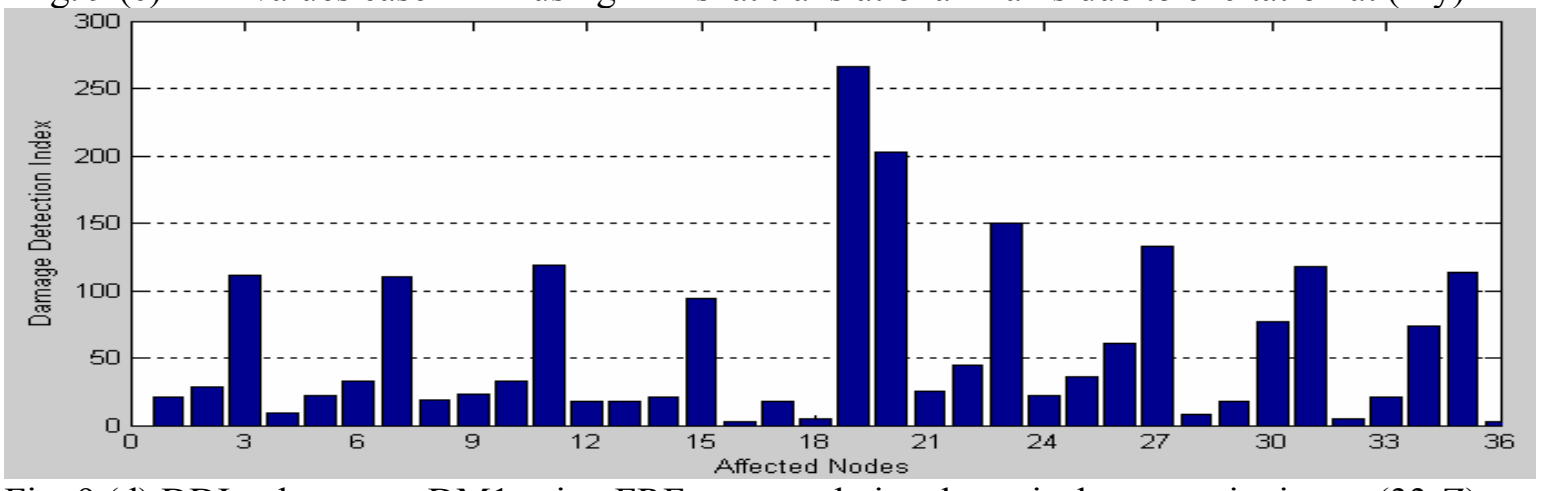

Fig. 9 (d) DDI values case DM1 using FRFs at translational $x$-axis due to excitation at (33-Z) 


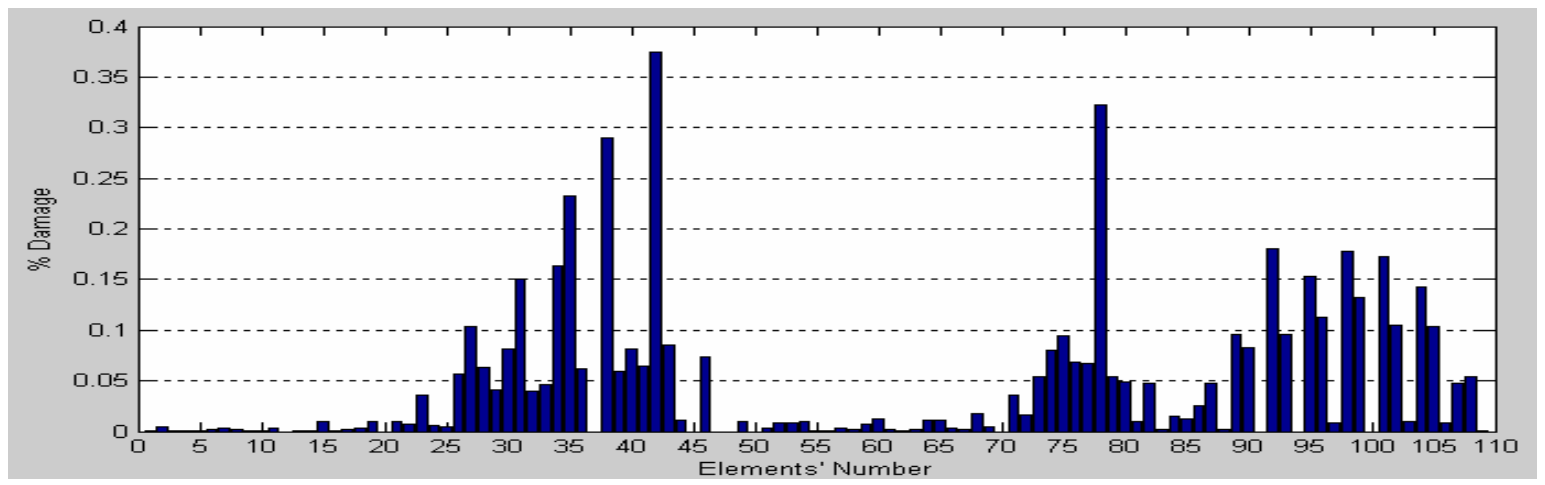

Fig. 10 (a) Damage identification results for damage case DM2 using 109elements

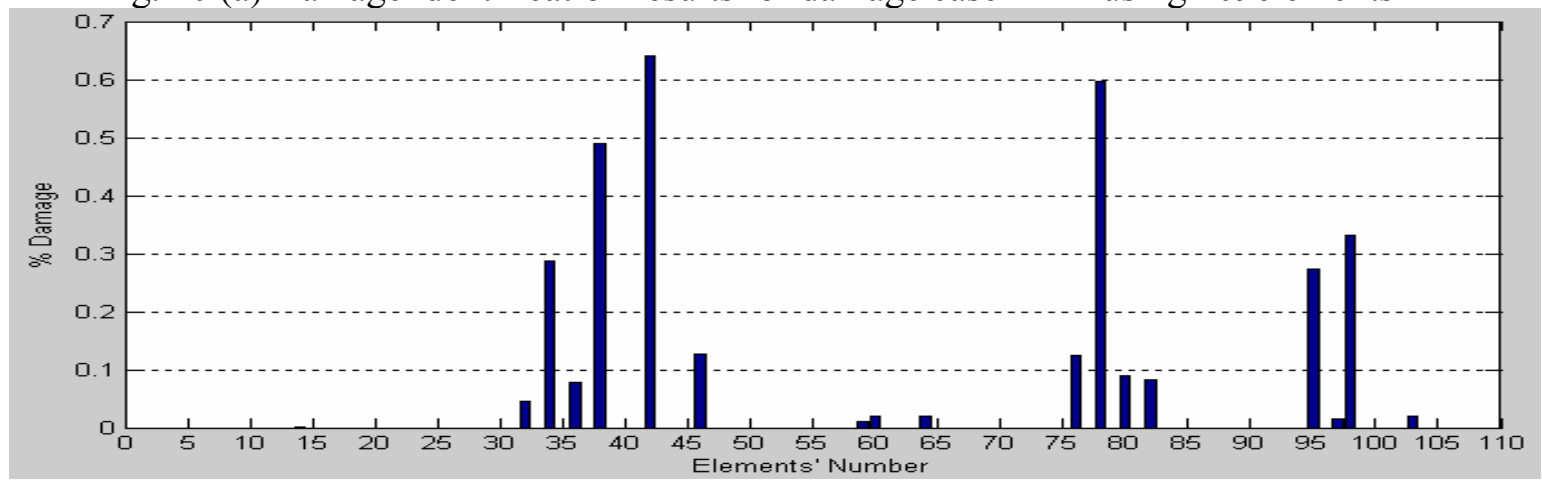

Fig. 10 (b) damage identification case DM2 based on region identification using DDI

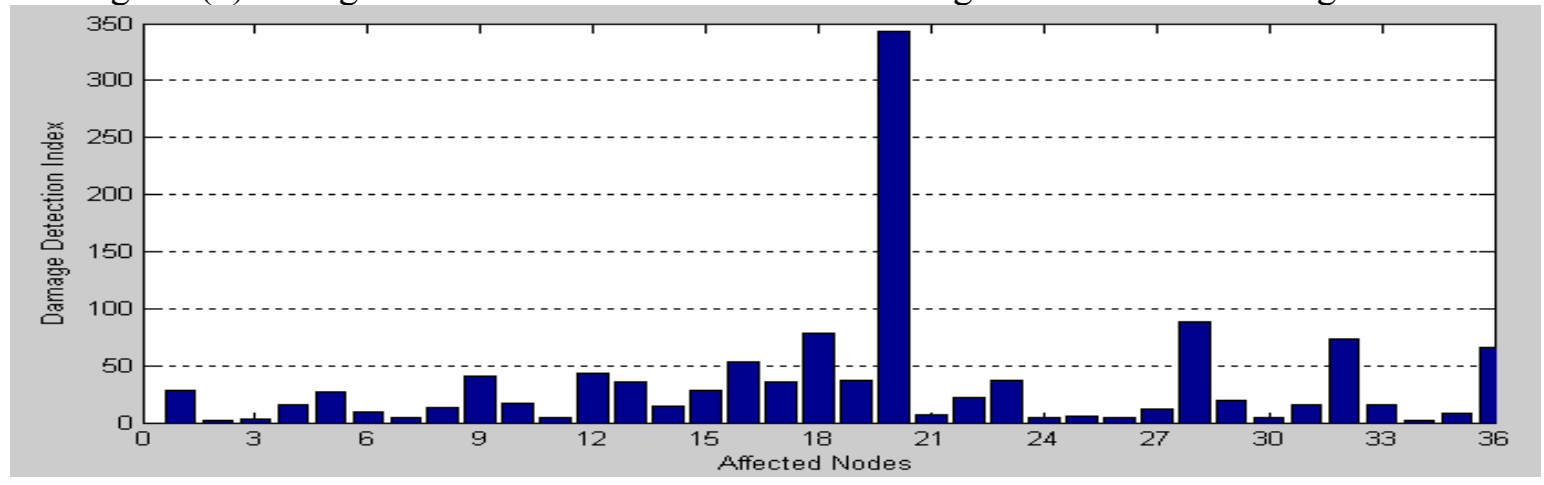

Fig. 10 (c) DDI values case DM2 using FRFs at translational x-axis due to excitation at (2-y)

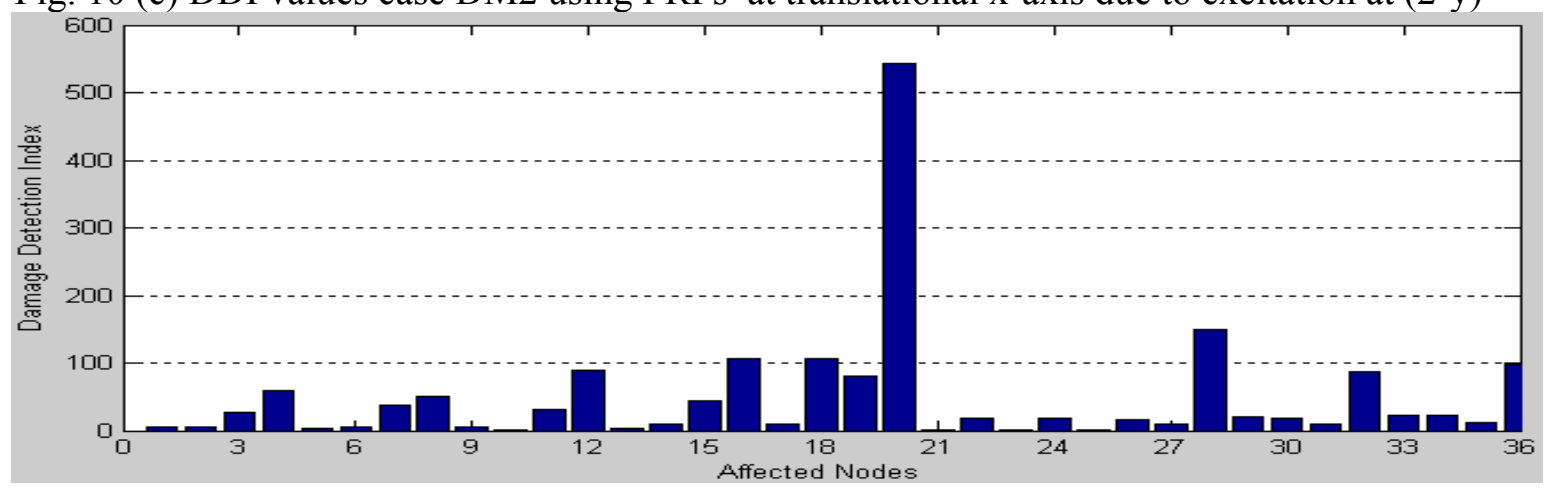

Fig. 10 (d) DDI values case DM2 using FRFs at translational x-axis due to excitation (33-Z) 